This article can be cited as: Rabat, Á., Tomás, R., Cano, M., Miranda, T., 2020. Impact of Water on Peak and Residual Shear Strength Parameters and Triaxial Deformability of High-Porosity Building Calcarenite Stones: Interconnection with their Physical and Petrological Characteristics. Constr. Build. Mater. 262, 120789. https://doi.org/10.1016/j.conbuildmat.2020.120789.

\title{
IMPACT OF WATER ON PEAK AND RESIDUAL SHEAR STRENGTH PARAMETERS AND TRIAXIAL DEFORMABILITY OF HIGH-POROSITY BUILDING CALCARENITE STONES: INTERCONNECTION WITH THEIR PHYSICAL AND PETROLOGICAL CHARACTERISTICS
}

\author{
Á. Rabat ${ }^{\mathrm{a}}$, R. Tomás ${ }^{\mathrm{a}}, \mathrm{M} . \mathrm{Cano}^{\mathrm{a}}$, T. Miranda ${ }^{\mathrm{b}}$ \\ a Departamento de Ingeniería Civil, Escuela Politécnica Superior, Universidad de Alicante, P.O. Box 99, E- \\ 03080 Alicante, Spain
}

b ISISE, Department of Civil Engineering, University of Minho, 4800-058 Guimarães, Portugal

* Corresponding author. alvaro.rabat@ua.es

\section{Abstract}

Several studies have found that water can cause substantial reductions of mechanical properties of building stones such as unconfined compressive strength, tangent Young's modulus or tensile strength. However, the influence of water content on shear strength parameters, triaxial compressive strength and modulus of elasticity under different confining pressures has been scarcely examined. For this reason, the present paper assesses the impact of water on peak and residual compressive strength and tangent Young's modulus of three porous building geomaterials widely used in civil and architectural constructions under different confining pressure through triaxial compressive tests. Furthermore, the corresponding peak and residual shear strength parameters computed from Mohr-Coulomb ( $c$ and $\phi)$ and from HoekBrown $\left(\sigma_{\mathrm{ci}}\right.$ and $m_{\mathrm{i}}$ ) failure criteria are obtained under dry and saturated conditions. Complementary physical and petrological analyses are performed in order to understand the main causes of the effect of water observed in these rock materials. The results indicate that water causes significant reductions of peak and residual compressive strength and tangent Young's modulus in the tested porous building stones for all the different applied confining pressures. Additionally, important changes of peak and residual shear strength parameters $\left(c, \phi, \sigma_{\mathrm{ci}}\right.$ and $\left.m_{\mathrm{i}}\right)$ are exhibited by the studied stones when become saturated. This could be related to physicochemical changes such as the hydrolysis of quartz and silicates in crack tip region inducing subcritical crack growth (stress corrosion), the decrease of the cement quality and the deterioration of the intergranular bonds due to the dispersion or dissolution of some minerals (calcite or chlorite) and the formation of microcracks caused by the swelling of the clay minerals present in these materials when they come into contact with water.

\section{Keywords}

Triaxial compression tests, water-weakening effect, porous building stones, shear strength parameters

\author{
List of symbols \\ $\rho_{\text {dry: }}$ Dry density \\ $\rho_{\text {sat: }}$ Saturated density \\ $\rho_{\mathrm{t}}$ : Particle density \\ $p_{\mathrm{o}}$ : Open porosity \\ $p$ : Total porosity \\ $W_{a}$ : Water absorption \\ $V_{p}$ : P-wave velocity \\ Vs: S-wave velocity \\ $d$ : Pore diameter \\ $E_{\mathrm{t}}$ : Tangent Young's modulus
}


This article can be cited as: Rabat, Á., Tomás, R., Cano, M., Miranda, T., 2020. Impact of Water on Peak and Residual Shear Strength Parameters and Triaxial Deformability of High-Porosity Building Calcarenite Stones: Interconnection with their Physical and Petrological Characteristics. Constr. Build. Mater. 262, 120789. https://doi.org/10.1016/j.conbuildmat.2020.120789.

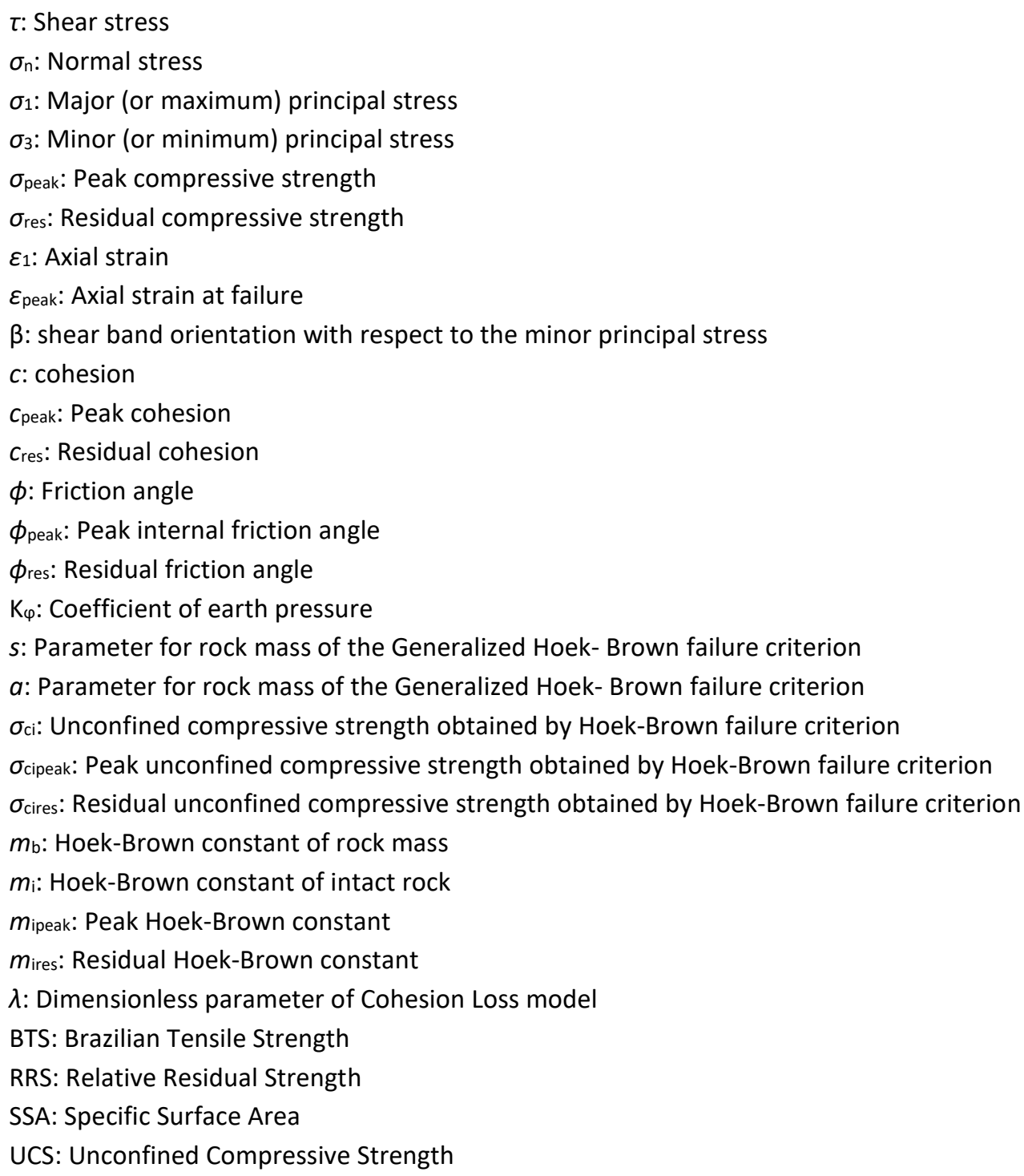

\section{INTRODUCTION}

Compressive strength and deformability are the main mechanical properties of geomaterials. The value of these properties strongly depends on a large number of petrological variables such as porosity, chemical and mineralogical composition, grain size and shape or anisotropy. However, external environmental aspects such as temperature, moisture content or confining pressure also play an essential role in the mechanical behaviour of rock materials [1]-[3]. Particularly, small variations of water content could lead to important variations in the abovementioned mechanical parameters, and can cause deterioration and damage in structural elements such as bridge piers and abutments, stone masonry walls, heritage buildings or ornamental components [4]-[7]. Furthermore, an in-depth knowledge of the effect of water-rock material interactions on the mechanical behaviour of geomaterials is also crucial for solving many relevant situations in several engineering activities such as mining, slope stability, subsurface fluid waste disposal, tunnelling or groundwater withdrawal [8], [9].

A large number of studies have shown that unconfined compressive strength (UCS), tangent Young's modulus $\left(E_{\mathrm{t}}\right)$ and Brazilian tensile strength (BTS) of sedimentary rock materials are greatly influenced by 
This article can be cited as: Rabat, Á., Tomás, R., Cano, M., Miranda, T., 2020. Impact of Water on Peak and Residual Shear Strength Parameters and Triaxial Deformability of High-Porosity Building Calcarenite Stones: Interconnection with their Physical and Petrological Characteristics. Constr. Build. Mater. 262, 120789. https://doi.org/10.1016/j.conbuildmat.2020.120789.

water saturation. Regarding sandstones, Price [10] and Mann and Fatt [11] observed reductions of 55\% in the UCS and of $8-20 \%$ in the $E_{\mathrm{t}}$ when these stones became saturated. Afterwards, other authors such as Dyke and Dobereiner [12], Hawkins and McConnell [13], Shakoor and Barefield [14] or Verstrynge et al. [15] found that UCS reductions due to water saturation ranged from 20 to $80 \%$ depending mainly on their petrographic characteristics and their clay content in numerous samples collected from several locations of Europe and USA. Concerning shales, mudstones and clay shales, Lashkaripour and Ajalloeian [16] and Jiang et al. [17] reported UCS and $E_{\mathrm{t}}$ reductions between 80 and 90\%. In limestones, Vásárhelyi [18] reported decreases of $34 \%$ in both the UCS and the $E_{\mathrm{t}}$ due to water saturation, while Cherblanc et al. [19] reported UCS losses of 30-60\% and BTS reductions of 28-64\%. In addition, Török and Vásárhelyi [20] obtained UCS decreases of $11 \%$ in travertines. In clay-bearing rocks, Erguler and Ulusay [21] found that water saturation caused UCS, $E_{\mathrm{t}}$ and BTS reductions up to 90, 93 and 90\%, respectively. Also, in gypsums, Yilmaz [22] and Rabat et al. [23] reported UCS and $E_{\mathrm{t}}$ average decreases of $62-65 \%$ and $34-46 \%$, respectively.

Furthermore, as also described by Mohr-Coulomb and Hoek-Brown failure criteria, when the confining pressure increases, the strength of rock materials also increases. In this sense, experimental studies can be performed at different conditions such as brittle, transitional and ductile regimes, depending on the confining pressure reached. Although some papers have correlated microstructural characteristics or permeability with mechanical properties of rock materials at different regimes [1], [24], [25], relatively few laboratory work has been performed in order to evaluate the water effect on peak and residual compressive strength, shear strength parameters or deformability of porous stones by triaxial tests.

In this connection, Baud et al. [3] compared the water-weakening effect in the brittle faulting and cataclastic flow regimes for several sandstones and concluded that inelastic behaviour and failure mode of dry and water-saturated samples were quite similar and that the reduction of compressive strength ranged from 5 to $17 \%$ in brittle faulting regime and between 20 to $70 \%$ in the cataclastic flow regime when these materials become saturated. Li et al. [26] found that, for intact rock materials, water saturation caused a reduction of cohesive strength and insignificant changes of basic friction angle, while for broken samples the shear strength reductions were caused by the deterioration of the residual friction angle. Chang and Haimson [27] carried out true triaxial experiments in rhyolite and obtained that the strength of "wet" samples (unjacketed specimens in direct contact with the confining fluid) was only 60 to $85 \%$ of the strength of dry samples (jacketed specimens to prevent confining fluid penetration), depending on the magnitude of the intermediate principal stress. Duda and Renner [8] observed that the strength reduction ranged from 13 to $23 \%$ for three types of sandstones under triaxial conditions. In contrast, Reviron et al. [28] reported that water had not notable effect on the critical stress levels in Bentheim sandstone, and concluded that the quasi-exclusive presence of quartz grains bonded together by a quartzose cement and the absence of clayey minerals may explain this behaviour. Wasantha and Ranjith [9] obtained that peak strength dropped from 13 to $38 \%$ at confining pressures from 4 to $25 \mathrm{MPa}$ due to water saturation as well as that the residual strength increased with confining pressure for both dry and saturated samples in Hawkesbury sandstone. Li et al. [29] found that the reduction of strength caused by water saturation is mainly related to a decrease of the friction angle in the Mohr-Coulomb failure criterion and to a reduction of the parameter $m_{i}$ in the Hoek-Brown failure criterion for metasedimentary rock materials from Singapore.

Failure patterns of porous rock materials under triaxial compression have been another traditional topic of research. Bésuelle et al. [30] found that the angle of shear plane with respect to the major principal stress increased with the confining pressure in sandstones. They also observed that bands became more numerous when the confining pressure rose. Mair et al. [25] demonstrated the importance of confining 
This article can be cited as: Rabat, Á., Tomás, R., Cano, M., Miranda, T., 2020. Impact of Water on Peak and Residual Shear Strength Parameters and Triaxial Deformability of High-Porosity Building Calcarenite Stones: Interconnection with their Physical and Petrological Characteristics. Constr. Build. Mater. 262, 120789. https://doi.org/10.1016/j.conbuildmat.2020.120789.

pressure on deformation band style within an overall brittle regime for porous sandstones, confirming that deformation band style was strongly sensitive to burial depth. A similar finding was noticed by Sulem and Ouffroukh [31] in a saturated sandstone through drained and undrained triaxial tests. Furthermore, they observed that the porosity increased in the shear band at low confining pressure and decreased at high confining pressure and that an important reduction of permeability happened in both cases. Wasantha and Ranjith [9] obtained that both dry and saturated samples of Hawkesbury sandstone failed by shear localization with only one shear region crossing each specimen. These authors also concluded that the angle of the failure plane with respect to the minor principal stress $(\beta)$ ranged from 55 to $45^{\circ}$ in dry samples and from 50 to $40^{\circ}$ in saturated samples when confining pressure varied from 4 to $25 \mathrm{MPa}$.

Calcarenite rocks are common in south-eastern part of Spain and some of them have been traditionally used as construction materials in emblematic building in this region. Specifically, in this work, three porous building stones with open porosities ranging from 10 to $18 \%$ and widely utilised in architectural constructions (monuments, emblematic buildings, stone masonry walls, building facades and decorative features) and civil engineering elements (bridge pillars, retaining systems, rockfills and foundations) were studied. Preliminary UCS tests carried out in quite similar materials showed that water saturation can cause significant reductions on their UCS when are saturated [32]. However, the influence of water under triaxial compression, which denotes a more genuine behaviour in specific situations, has not been studied in these building calcarenite stone varieties until now. In this connection, nowadays, heritage stone structures sometimes require a structural retrofitting (strengthening intervention) to guarantee their safety due to durability issues such as the stone degradation caused by humidity problems related to ground water penetration [33] or accidental situations (explosions or fire-exposure) [34]. In the particular case of stone columns, one of the most frequent solutions includes the increase of the compressive strength by means of lateral confinement using steel elements or composite materials (CFRP or GFRP) [33]. As a consequence, a detailed characterization of stone materials exposed to different confinement pressures can be used to make preliminary approximations of the effect of retrofitting or reinforcement solutions in these cases. Also, the determination of the effect of water and confinement on strength and deformability of stone materials is relevant for the safety evaluation of stone pillars of older bridges, which are frequently exposed to water saturation and to different confining pressures due to variations of the hydrostatic thrusts during their lifetime.

Therefore, this study tries to fill the large gap found in the literature regarding the mechanical behaviour of these materials under different confining pressures and provides their shear strength parameters in dry and saturated conditions. In detail, the main objectives of this work are: (1) to study the variations of peak and residual compressive strength and tangent Young's modulus due to water saturation for different confining pressures; (2) to estimate the effect of water on the corresponding shear strength parameters computed through Mohr-Coulomb and Hoek-Brown failure criteria; (3) to assess and compare the failure mode and the shear band orientation depending on the confining pressure and the water content of the specimens; and (4) to understand more deeply the water-weakening effect in these porous building geomaterials.

\section{TESTED BUILDING STONES AND METHODOLOGY}

\subsection{Sample preparation}

Building materials used in this study are three fine- and medium-grained calcarenites widely present in the province of Alicante (SE Spain). These building stones belong to a Middle-Late Miocene unit from the Betic-Balearic domain. Specifically, intact blocks of the three stone types (hereinafter referred to as R-1, R-2 and R-3) were taken from an active quarry located in the municipality of Elda (W Alicante) and 
This article can be cited as: Rabat, Á., Tomás, R., Cano, M., Miranda, T., 2020. Impact of Water on Peak and Residual Shear Strength Parameters and Triaxial Deformability of High-Porosity Building Calcarenite Stones: Interconnection with their Physical and Petrological Characteristics. Constr. Build. Mater. 262, 120789. https://doi.org/10.1016/j.conbuildmat.2020.120789.

transported to laboratory (Figure 1b). Then, a total of 33 cylindrical core specimens (11 specimens from each rock block), $54 \mathrm{~mm}$ in diameter and $110 \mathrm{~mm}$ in length, were drilled perpendicular to the sedimentary bedding by using a diamond drill rig and tap water as a cooling fluid (Figure $1 \mathrm{a}$ and $\mathrm{c}$ ). One of these specimens of each calcarenite type was reserved to check the reproducibility of triaxial strength tests. The ends of specimens were cut and ground parallel to each other and at right angles to the longitudinal axis following the corresponding ISRM Suggested Method [35] in order to avoid problems during the tests [36]. That is, the ends of the specimens were flat to $\pm 0.01 \mathrm{~mm}$ and were not departed from the perpendicular to the longitudinal axis of the specimen by more than 0.001 rad. Additionally, the sides of the specimens were smooth and free of abrupt irregularities and straight to within $0.3 \mathrm{~mm}$ over the full length of the specimens.

Afterwards, the specimens were dried at $70^{\circ} \mathrm{C}$ and at atmospheric pressure inside a ventilated oven until a constant mass was reached (the difference between two weighings carried out in a 24-hour interval was not greater than $0.1 \%$ of the mass of the sample) (Figure $1 d$ ). Then, the specimens were kept in a desiccator until they reached room temperature $\left(20 \pm 5^{\circ} \mathrm{C}\right)$ and later their dry mass was recorded. Subsequently, in order to obtain dry and fully saturated samples, half of the specimens of each stone variety were remained in dry conditions while the other half were immersed into distilled water within a container at atmospheric pressure (Fig. 1e).

To control the quantity of water absorbed by wet samples, at certain time intervals, the specimens were removed from the container, dried slightly at room temperature with a damp cloth to remove the water droplets of their surface and their wet masses were determined. This procedure was repeated until obtaining a constant weight of the specimens (saturated mass), which was reached in a water immersion time less than five days for all specimens. However, overall exposure time to distilled water for all saturated samples was two weeks before triaxial testing.
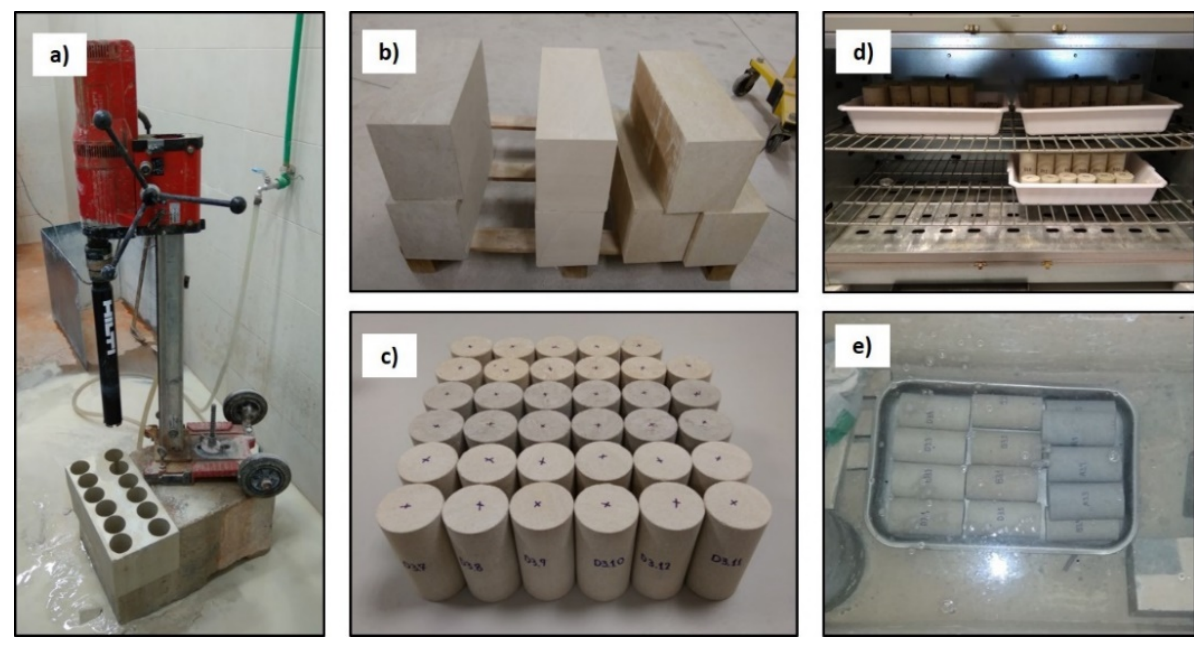

Fig. 1. Specimen preparation. a) Extraction of cylindrical core samples with a diamond drill rig. b) Intact rock blocks of dimensions $40 \times 20 \times 15 \mathrm{~cm}^{3}$. c) Prepared specimens with $54 \mathrm{~mm}$ in diameter and $110 \mathrm{~mm}$ in length. d) Specimen drying in an oven at $70^{\circ} \mathrm{C}$. e) Specimen saturation by soaking in distilled water.

\subsection{Mineralogical characterisation}

Petrographic analyses were performed using an OPTIKA B600POL microscope with the X4 objective lens. The thin-sections were prepared in direction normal to the sedimentary bedding planes and were observed with parallel (PN) and crossed (CN) nicols. 
This article can be cited as: Rabat, Á., Tomás, R., Cano, M., Miranda, T., 2020. Impact of Water on Peak and Residual Shear Strength Parameters and Triaxial Deformability of High-Porosity Building Calcarenite Stones: Interconnection with their Physical and Petrological Characteristics. Constr. Build. Mater. 262, 120789. https://doi.org/10.1016/j.conbuildmat.2020.120789.

The structure and mineralogy of building stones were examined using Scanning Electron Microscope Technique (SEM). SEM measurements were done using a Merlin VP compact device (Zeiss, Oberkochen, Germany). Furthermore, additional EDX investigations were performed using a Quantax 400 device (Bruker, Billerica, MA, USA). The accelerating voltage used for this work was $20 \mathrm{kV}$. The samples were made conductive by coating them with gold.

XRD analyses were performed through a Bruker D8-Advance X-Ray diffractometer (Bruker, Billerica, MA, USA) with a generator of $X$ ray KRISTALLOFLEX K 760-80F (Bruker, Billerica, MA, USA) and a XR tube with a copper anode.

\subsection{Physical characterisation}

Dry $(\rho \mathrm{dry})$ and saturated ( $\left.\rho_{\text {sat }}\right)$ bulk densities were calculated as the quotient between the dry and the saturated weights, respectively, and the bulk volume of the samples according to Spanish standard UNEEN 1936 [37]. Specifically, the specimen's volume was calculated from diameter and length measurements (caliper method). Particle density $\left(\rho_{\mathrm{t}}\right)$ was determined from powder samples using the pycnometers method as established in UNE 103-302-94 standard [38].

Open porosity $\left(p_{0}\right)$ and water absorption $\left(W_{a}\right)$ were obtained using weights (i.e. dry, saturated-surfacedry and saturated-submerged) and bulk volume, following the UNE-EN-1936 standard [37]. All these properties were determined only using those specimens which were triaxially tested under saturated conditions (i.e., the half of the total number of specimens). In addition, total porosity $(p)$ was computed from dry unit weight and the particle density of the stones [37].

$\mathrm{P}$ - and S- wave velocities ( $\mathrm{V}$ and $\mathrm{Vs}$, respectively) were determined from the ratio of the sample length to the transit time of the pulse obtained by using a signal emitting-receiving (Proceq Pundit Lab+) coupled with a PC and two ultrasound transducers with a central frequency of $250 \mathrm{kHz}$, according to the UNE-EN 14579 standard [39].

Pore-size distribution and porosity of the building materials were determined through Mercury Intrusion Porosimetry (MIP) technique using a POREMASTER-60GT system (Quantachrome Instruments, Boyton Beach, FL, USA) equipped with two low pressure stations and two others high pressure stations.

\subsection{Triaxial compression tests}

\subsubsection{Testing equipment and procedure}

Triaxial compressive tests were performed using an equipment composed of: a) a loading machine for applying, controlling and measuring the axial load through an electronic control (accuracy of load cell of $0.01 \%$ ) (Figure 2a); b) a Hoek triaxial cell (Figures $2 \mathrm{~b}$ and c); c) a hydraulic pump capable of maintaining a constant confining pressure (Figure $2 \mathrm{~d}$ ) equipped with pressure indicating devices (pressure transducers, accuracy $0.1 \%$ ) to measure the confining pressure values; and d) a data acquisition and display system to record the axial forces, the axial displacements, the confining pressures and the time during the test. 
This article can be cited as: Rabat, Á., Tomás, R., Cano, M., Miranda, T., 2020. Impact of Water on Peak and Residual Shear Strength Parameters and Triaxial Deformability of High-Porosity Building Calcarenite Stones: Interconnection with their Physical and Petrological Characteristics. Constr. Build. Mater. 262, 120789. https://doi.org/10.1016/j.conbuildmat.2020.120789.
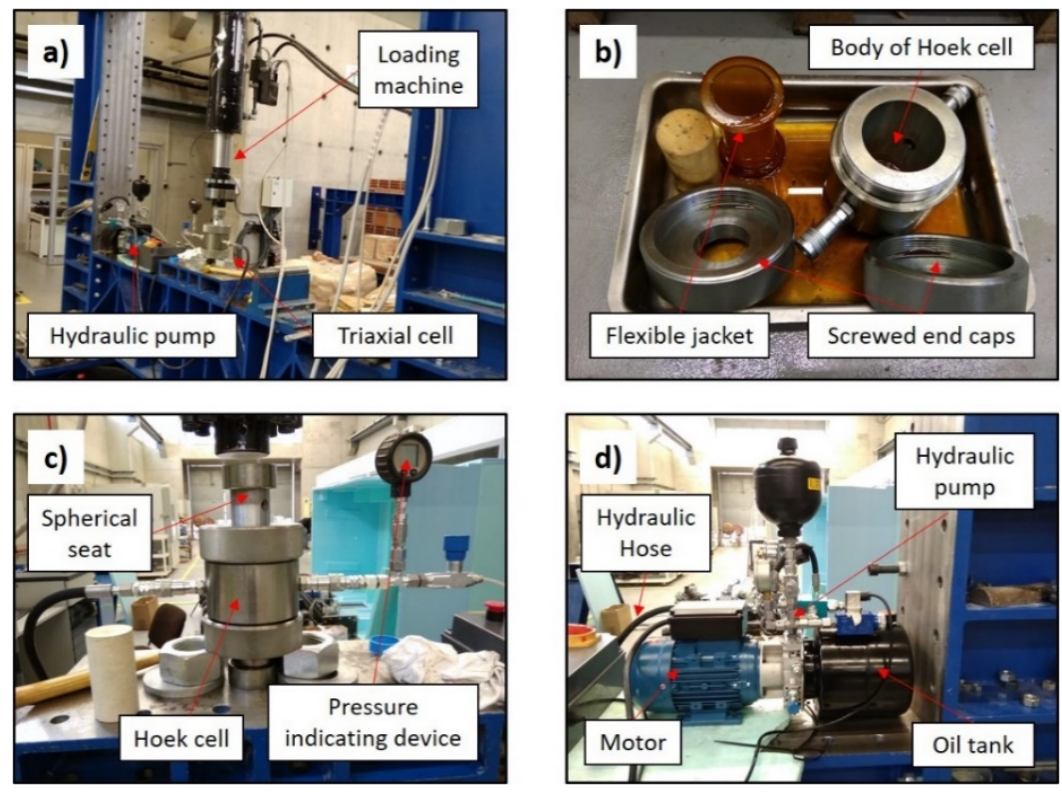

Fig. 2. Equipment used in the triaxial compression tests: a) Loading machine. b) Components of the triaxial cell. c) Triaxial cell assembled and pressure indicating devices. d) Hydraulic pump.

The tests were carried out in accordance with ISRM Suggested Method [35]. Firstly, the additional specimens prepared to check the reproducibility of triaxial tests were tested in dry conditions under the highest confining pressure values used in the subsequent experiments ( $16 \mathrm{MPa}$ ) with the aim of verifying also that the failure would occur for axial forces lower than the load capacity of the testing machine. Afterwards, the bulk of the experimental campaign was carried out. Particularly, confining pressures of $0.0,4.0,8.0,12.0$ and $16.0( \pm 0.1) \mathrm{MPa}$ (uncertainty of $2.5 \%$ ) were applied for dry and saturated specimens of each type of building stone under undrained conditions. The same assembly (including piston) was used for testing all samples and the water of saturated samples was not allowed to drain through either side. A linear variable differential transformer (LVDT) (accuracy of $0.1 \%$ ) mounted outside the triaxial cell and between the moving piston and the fixed lower platen was used to measure the displacement.

The testing procedure can be summarized as follows: Firstly, the loading piston was contacted with the specimen assembly and the axial displacement was set to zero. Then, the axial load and the confining pressure were gradually increased simultaneously until the predetermined value for the confining pressure was achieved. Afterwards, the compression test was performed by increasing the axial load at a constant axial strain rate between the limits of $2 \cdot 10^{-5}$ and $3 \cdot 10^{-5} \mathrm{~s}^{-1}$, keeping the confining pressure constant. Finally, after the failure of the sample (peak stress), the system gradually reduced the axial load by the strain rate control in order to obtain the post-peak behaviour.

The axial force and displacement values were recorded during the entire course of the tests in order to determine the corresponding mechanical parameters. Specifically, with the knowledge of the stiffness of the loading system, the displacement of the specimens was obtained by subtracting the displacement of the loading system from the apparent displacement recorded by the LVDT. Tangent Young's modulus was then determined as the slope of a line tangent to the stress-strain curve at a $50 \%$ of the ultimate compressive strength for each stone specimen, following the corresponding ISRM Suggested Methods [40]. The residual strength of the stones was defined as the plateau after the peak stress and in a strain of about 1.5 times of the strain that corresponds to the peak strength. Lengths and diameters of specimens obtained before assembling the triaxial cell were used to determine stresses and strains, that 
This article can be cited as: Rabat, Á., Tomás, R., Cano, M., Miranda, T., 2020. Impact of Water on Peak and Residual Shear Strength Parameters and Triaxial Deformability of High-Porosity Building Calcarenite Stones: Interconnection with their Physical and Petrological Characteristics. Constr. Build. Mater. 262, 120789. https://doi.org/10.1016/j.conbuildmat.2020.120789.

is, the variations of the dimensions of the specimens caused by the application of confining pressures and deviatoric forces were not considered to calculate strength and deformability values. The relative error in stress derived from this assumption was less than $1.5 \%$.

\subsubsection{Mohr-Coulomb and Hoek-Brown failure criteria}

On the one hand, the Mohr-Coulomb failure criterion has been traditionally used for the mechanical characterization of geomaterials in geotechnical applications. It describes a linear relationship between normal $\left(\sigma_{\mathrm{n}}\right)$ and shear $(\tau)$ stresses at failure (Eq. 1):

$\tau=c+\sigma_{\mathrm{n}} \cdot \tan \varphi$

where $c$ is the cohesion and $\phi$ the friction angle. Thus, this failure criterion can also be expressed as a function of major $\left(\sigma_{1}\right)$ and minor $\left(\sigma_{3}\right)$ principal stresses:

$\sigma_{1}=2 \cdot c \cdot \frac{\cos \varphi}{1-\sin \varphi}+\sigma_{3} \cdot \frac{1+\sin \varphi}{1-\sin \varphi} \quad$ (Eq. 2)

where the first term of the Eq.2 is the uniaxial compressive strength, and the slope of the line is the coefficient of earth pressure $\left(\mathrm{K}_{\varphi}\right)$. Due to the mathematical simplicity and clear physical meaning of the parameters, this model is frequently used to obtain the corresponding peak and residual shear strength parameters of intact rocks [41].

On the other hand, an alternative non-linear empirical failure model widely used for rocks masses is the Generalized Hoek-Brown criterion [42], [43], which is defined by:

$\sigma_{1}=\sigma_{3}+\sigma_{\mathrm{ci}} \cdot\left(m_{\mathrm{b}} \cdot \frac{\sigma_{3}}{\sigma_{\mathrm{ci}}}+s\right)^{a} \quad(\mathrm{Eq} \cdot 3)$

where $\sigma_{\mathrm{ci}}$ is the uniaxial compressive strength (UCS) of intact rock, and $m_{\mathrm{b}}, \mathrm{s}$ and $a$ are parameters for rock masses. For intact rock, $s$ is equal to 1 and $a$ is equal to 0.5 , and the model can be simplified as:

$\sigma_{1}=\sigma_{3}+\sigma_{\mathrm{ci}} \cdot\left(m_{\mathrm{i}} \cdot \frac{\sigma_{3}}{\sigma_{\mathrm{ci}}}+1\right)^{0.5} \quad(\mathrm{Eq} \cdot 4)$

Therefore, the relationship between the principal stresses at failure is defined by two parameters, the unconfined compressive strength $\left(\sigma_{\mathrm{ci}}\right)$ and the Hoek-Brown constant $\left(m_{\mathrm{i}}\right)$. This model has been successfully used to capture the peak strength of most rock types over a wide range of confining pressures. Furthermore, since this model presents the advantage of describing a nonlinear increase in strength with increasing confinement, some researchers have successfully used it to describe the residual strength of intact rocks [44].

Nevertheless, parameter $s$ mainly depends on the degree of fragmentation of the rock and is analogous to the cohesion strength component in the Mohr-Coulomb model. Specifically, the maximum value of $s$ is 1 (intact rock) and the minimum value of $s$ is zero (heavily jointed or damage rock). In this sense, when a rock enters the residual deformation stage, the damage in the form of microcrack is significantly accumulated, resulting in a large loss of cohesion. For that reason, some researchers suggest that parameter $s$ can be generally considered as zero in the residual deformation stage. Based on Hoek-Brown model and these considerations, Peng and Cai [41] proposed the following Cohesion Loss model in order to specifically determine the residual strength of intact rocks:

$\sigma_{1}=\sigma_{3}+\left(\lambda \cdot \sigma_{c i} \cdot \sigma_{3}\right)^{0.5} \quad(\mathrm{Eq} .5)$

in which only one dimensionless parameter $\lambda$ controls the nonlinearity of the residual strength envelope. 
This article can be cited as: Rabat, Á., Tomás, R., Cano, M., Miranda, T., 2020. Impact of Water on Peak and Residual Shear Strength Parameters and Triaxial Deformability of High-Porosity Building Calcarenite Stones: Interconnection with their Physical and Petrological Characteristics. Constr. Build. Mater. 262, 120789. https://doi.org/10.1016/j.conbuildmat.2020.120789.

In this work, the cohesion $(c)$ and the friction angle $(\phi)$ of the Mohr-Coulomb failure criterion as well as the constant $\left(m_{\mathrm{i}}\right)$ and the uniaxial compression strength $\left(\sigma_{\mathrm{ci}}\right)$ of the Hoek-Brown failure criterion were calculated by entering the triaxial testing data into the RocData v5.0 software [45]. In particular, the envelopes (i.e. the peak and residual shear strength parameters) for the three building materials in dry and saturated conditions were obtained by fitting the corresponding strength values using the LevenbergMarquardt nonlinear regression method. Additionally, the residual strength envelopes were calculated using the Cohesion Loss model (parameter $\lambda$ ).

\section{RESULTS AND ANALYSIS}

\subsection{Mineralogical composition and petrographic analyses}

Building stones used in this work are composed of primary sediments belonging to the continental shelf with a discontinuous deposition of benthic, nektonic and planktonic organisms. They can be defined as biomicrites according to Folk's classification [46]. The three stone varieties are very homogeneous calcarenites without signs of microscopic anisotropy, and are mainly composed of calcite grains consisting of 0.1-0.5 mm-thick foraminifera and quartz grains with a diameter varying from 0.05 to $0.25 \mathrm{~mm}$. Thin sections and SEM microphotographs (Fig. 3) and XRD analyses (powder and oriented aggregates methods) (Fig. 4) revealed their specific petrological properties.

R-1 is a biomicrite mainly constituted of fossils, specifically foraminifera (Globigerina, Globorotalia, Textularidae and Rotalidae), bryozoans and echinoderms (mostly smaller than $0.4 \mathrm{~mm}$ ). Regarding terrigenous components, the most abundant are quartz (both monocrystalline and polycrystalline) with a grain size mainly ranging from 0.03-0.09 mm, potassium feldspar, dolostone extraclasts, phyllosilicates and clay galls. In addition, it has small quantities of orthochems (micritic matrix and sparry cement) and a siliceous fibrous cement in localised areas. The semiquantitative mineralogical analysis performed by XRD indicated that this stone consists in calcite (70-75\%), dolomite (5-10\%), quartz (10-15\%) and phyllosilicates (0-5\%). Concerning clay fraction, SEM revealed the presence of glauconite spherulites filling fossils and bending plate of illite-smectite [47], [48] (Figs. 3.a).

R-2 is a biomicrite mostly formed by fossil elements such as foraminifera (Rotalidae, Globigerina and Textularidae), bryozoans and molluscs (smaller than $0.3 \mathrm{~mm}$ ). The main terrigenous components are monocrystalline quartz, dolostone clasts and small amounts of feldspars $(0.05-0.25 \mathrm{~mm})$. The semiquantitative mineralogical analysis performed by XRD indicated that this building material consists in calcite $(65-70 \%)$, dolomite (5-10\%), quartz (15-20\%) and phyllosilicates (0-5\%). With regard to clay minerals, illite, fibrous aggregates of palygorskite and glauconite spherulites were observed through SEM technique [47], [48] (Figs. 3.b).

R-3 is a biomicrite mainly composed of fossil components smaller than $0.5 \mathrm{~mm}$ (Rotalidae, Globigerina, Turborotalia and Heterostegina). With respect to the terrigenous components, quartz (monocrystalline), potassium feldspar, schist and clay galls have been found $(0.05-0.20 \mathrm{~mm})$ in this stone. Regarding orthochems, micrite is the most abundant constituent. The semiquantitative mineralogical analysis performed by XRD indicated that this stone consists in calcite (75-80\%), dolomite (5-10\%), quartz (5-15\%) and phyllosilicates (5-10\%). Specifically, regarding to the presence of phyllosilicates, SEM demonstrated the existence of glauconite spherulites filling fossils or growing on calcite cement and also the presence of chlorite and illite-smectite [47], [48] (Figs. 3.c). 
This article can be cited as: Rabat, Á., Tomás, R., Cano, M., Miranda, T., 2020. Impact of Water on Peak and Residual Shear Strength Parameters and Triaxial Deformability of High-Porosity Building Calcarenite Stones: Interconnection with their Physical and Petrological Characteristics. Constr. Build. Mater. 262, 120789. https://doi.org/10.1016/j.conbuildmat.2020.120789.
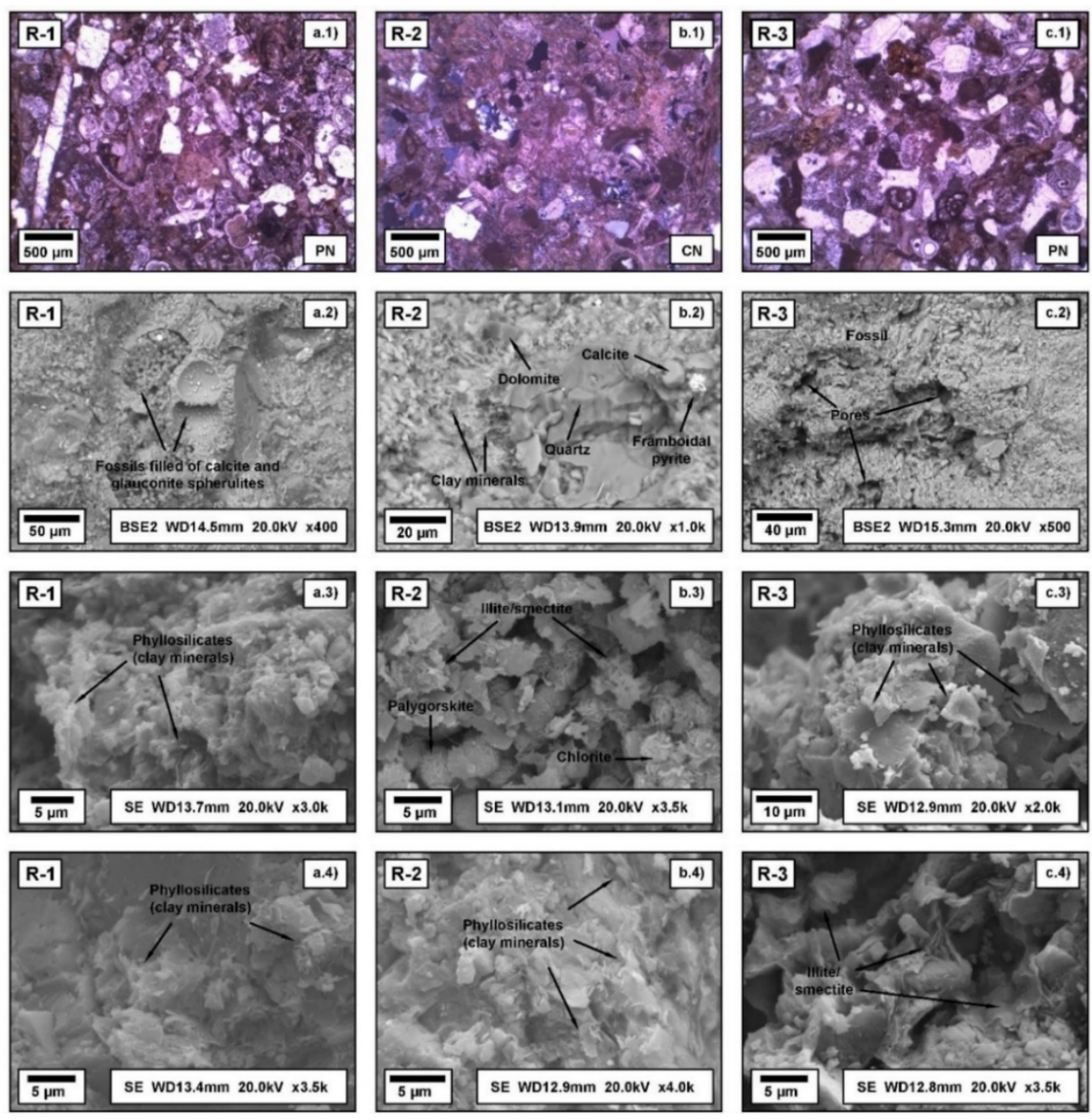

Fig. 3. Petrological and microscopic analyses. Thin section microphotographs taken with parallel (a.1 and c.1) and crossed (b.1) nicols (b.1) ; scanning electron microscopy (SEM) images showing typical fossils and minerals (a.2, b.2 and c.2) and details of phyllosilicates (a.3, b.3, c.3, a.4, b.4 and c.4) found in the three tested building stones.
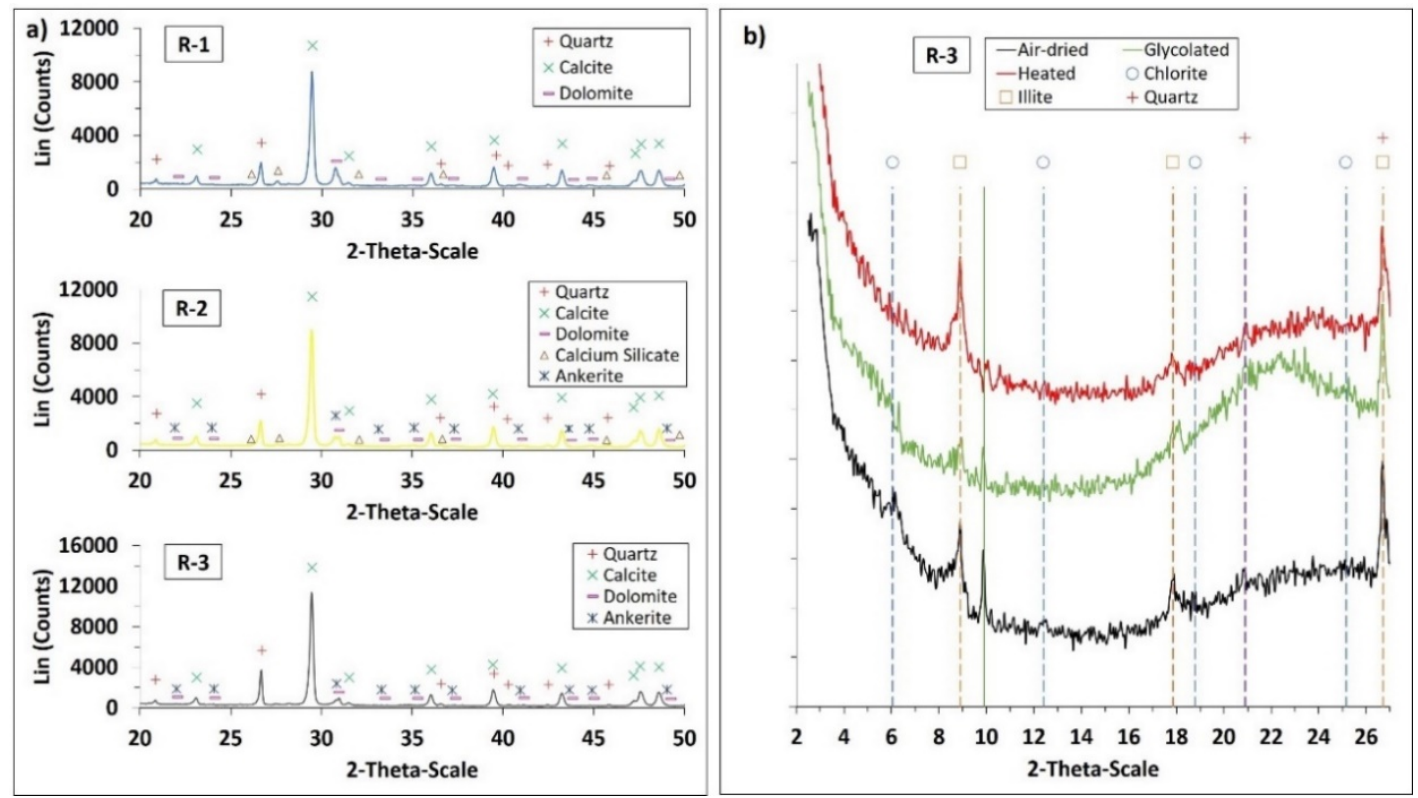
This article can be cited as: Rabat, Á., Tomás, R., Cano, M., Miranda, T., 2020. Impact of Water on Peak and Residual Shear Strength Parameters and Triaxial Deformability of High-Porosity Building Calcarenite Stones: Interconnection with their Physical and Petrological Characteristics. Constr. Build. Mater. 262, 120789. https://doi.org/10.1016/j.conbuildmat.2020.120789.

Fig. 4. (a) X-Ray diffractograms of the tested calcarenites (R-1, R-2 and R-3) (powder method) and (b) X-ray diffractograms of the residual fraction after calcite dissolution and exposing to different conditions -ethylene-glycol solvation, air drying and heating obtained in R-3 variety (oriented aggregates method).

\subsection{Physical properties}

Dry densities of the studied stones varied from 2.07 to $2.29 \mathrm{~g} / \mathrm{cm}^{3}$ while saturated densities ranged from 2.24 to $2.40 \mathrm{~g} / \mathrm{cm}^{3}$. Particularly, the highest value was obtained in R-1 and the lowest value was found in R-3. R-1 exhibited the lowest porosities (an open porosity of $10.7 \%$ and a total porosity of $14.9 \%$ ) and water absorption capacity (i.e. 4.7\%) while R-3 exhibited the highest mean values of these physical properties (i.e. 17.9, 23.8 and $8.7 \%$, respectively). R-2 showed intermediate values of density and porosity. Regarding ultrasonic wave velocities, the greatest values were measured in R-1 specimens (i.e. a P-wave velocity of $3.96 \mathrm{~km} / \mathrm{s}$ and a S-wave velocity of $2.13 \mathrm{~km} / \mathrm{s}$ ) while the smallest values were obtained in R-2 (i.e. a P-wave velocity of $3.38 \mathrm{~km} / \mathrm{s}$ and a S-wave velocity of $2.00 \mathrm{~km} / \mathrm{s}$ ). For its part, R-3 showed intermediate values (a P-wave velocity of $3.73 \mathrm{~km} / \mathrm{s}$ and a S-wave velocity of $2.02 \mathrm{~km} / \mathrm{s}$ ). Small standard deviations were found in these physical properties for each stone variety, which confirms the high homogeneity (or the low sample variability) of the tested calcarenite specimens (Table 1).

Table 1. Summary of physical properties of the building stones (mean value \pm standard deviation). $\rho_{\text {sat, }}, p_{\circ}$ and $W_{a}$ were determined using the corresponding saturated specimens ( 5 units of each stone variety).

\begin{tabular}{|c|c|c|c|}
\cline { 2 - 4 } \multicolumn{1}{c|}{} & \multicolumn{3}{c|}{ Building stone ID } \\
\hline Physical/ultrasonic property & R-1 & R-2 & R-3 \\
\hline Total number of samples $($ dry $/$ saturated) & $10(5 / 5)$ & $10(5 / 5)$ & $10(5 / 5)$ \\
\hline Dry density, $\rho_{\text {dry }}\left(\mathrm{g} / \mathrm{cm}^{3}\right)$ & $2.29 \pm 0.01$ & $2.23 \pm 0.02$ & $2.07 \pm 0.02$ \\
\hline Saturated density, $\rho_{\text {sat }}\left(\mathrm{g} / \mathrm{cm}^{3}\right)$ & $2.40 \pm 0.01$ & $2.37 \pm 0.02$ & $2.24 \pm 0.01$ \\
\hline Particle density, $\rho_{\mathrm{t}}\left(\mathrm{g} / \mathrm{cm}^{3}\right)$ & $2.69 \pm 0.01$ & $2.72 \pm 0.01$ & $2.71 \pm 0.01$ \\
\hline Open porosity, $p_{\mathrm{o}}(\%)$ & $10.74 \pm 0.15$ & $14.76 \pm 0.63$ & $17.85 \pm 0.63$ \\
\hline Total porosity, $p(\%)$ & $14.94 \pm 0.44$ & $18.07 \pm 0.80$ & $23.77 \pm 0.64$ \\
\hline Water absorption, $\mathrm{W}_{\mathrm{a}}(\%)$ & $4.69 \pm 0.05$ & $6.64 \pm 0.34$ & $8.65 \pm 0.37$ \\
\hline P-wave velocity, $\mathrm{vp}(\mathrm{km} / \mathrm{s})(\mathrm{dry}$ condition) & $3.96 \pm 0.05$ & $3.38 \pm 0.08$ & $3.73 \pm 0.08$ \\
\hline S-wave velocity, $\mathrm{vs}(\mathrm{km} / \mathrm{s})(\mathrm{dry}$ condition) & $2.13 \pm 0.02$ & $2.00 \pm 0.04$ & $2.02 \pm 0.07$ \\
\hline
\end{tabular}

Concerning the porous structure of the building stones studied through MIP (Figure 5), R-1 showed the smallest values of pore size (diameters mostly between 0.01 and $0.7 \mu \mathrm{m}$ ) and total porosity (13.3\%) and the greatest values of specific surface area (SSA) $\left(5.53 \mathrm{~m}^{2} / \mathrm{g}\right)$. This material exhibited abundant intraparticle porosity (11.8\%) and scarce interparticle porosity (1.5\%). R-2 and R-3 showed a quite similar pore size distribution, with diameter values mostly in the range of 0.1-20.0 $\mu \mathrm{m}$ and with specific surface areas of 3.16 and $3.22 \mathrm{~m}^{2} / \mathrm{g}$, respectively. However, it is important to note that, although the total porosity of R-2 (18.7\%) is smaller than that of R-3 (20.5\%), R-2 displays a greater intraparticle porosity than R-3 (15.9\% versus $12.2 \%)$ and a lower interparticle porosity (2.8\% versus $8.3 \%)$.

These characteristics of the pore networks could explain the different values of P-wave velocities measured in each calcarenite type. On the one hand, the greatest P-wave velocity obtained in R-1 can be attributed to its smaller porosities (both interparticle and intraparticle porosities). On the other hand, the lower P-wave velocity measured in R-2 compared to R-3 could be justified by its higher intraparticle porosity (despite that the total porosity of R-2 is smaller than that of R-3). That is, R-2 behaves more like a non-continuous solid as P-wave cannot propagate through these intraparticle pores with high aspect ratio, while R-3 behaves as a more continuous solid due to the presence of more interparticle pores with 
This article can be cited as: Rabat, Á., Tomás, R., Cano, M., Miranda, T., 2020. Impact of Water on Peak and Residual Shear Strength Parameters and Triaxial Deformability of High-Porosity Building Calcarenite Stones: Interconnection with their Physical and Petrological Characteristics. Constr. Build. Mater. 262, 120789. https://doi.org/10.1016/j.conbuildmat.2020.120789.

lower aspect ratio (cements and matrix between grains) through which P-wave propagates more easily [49], [50].
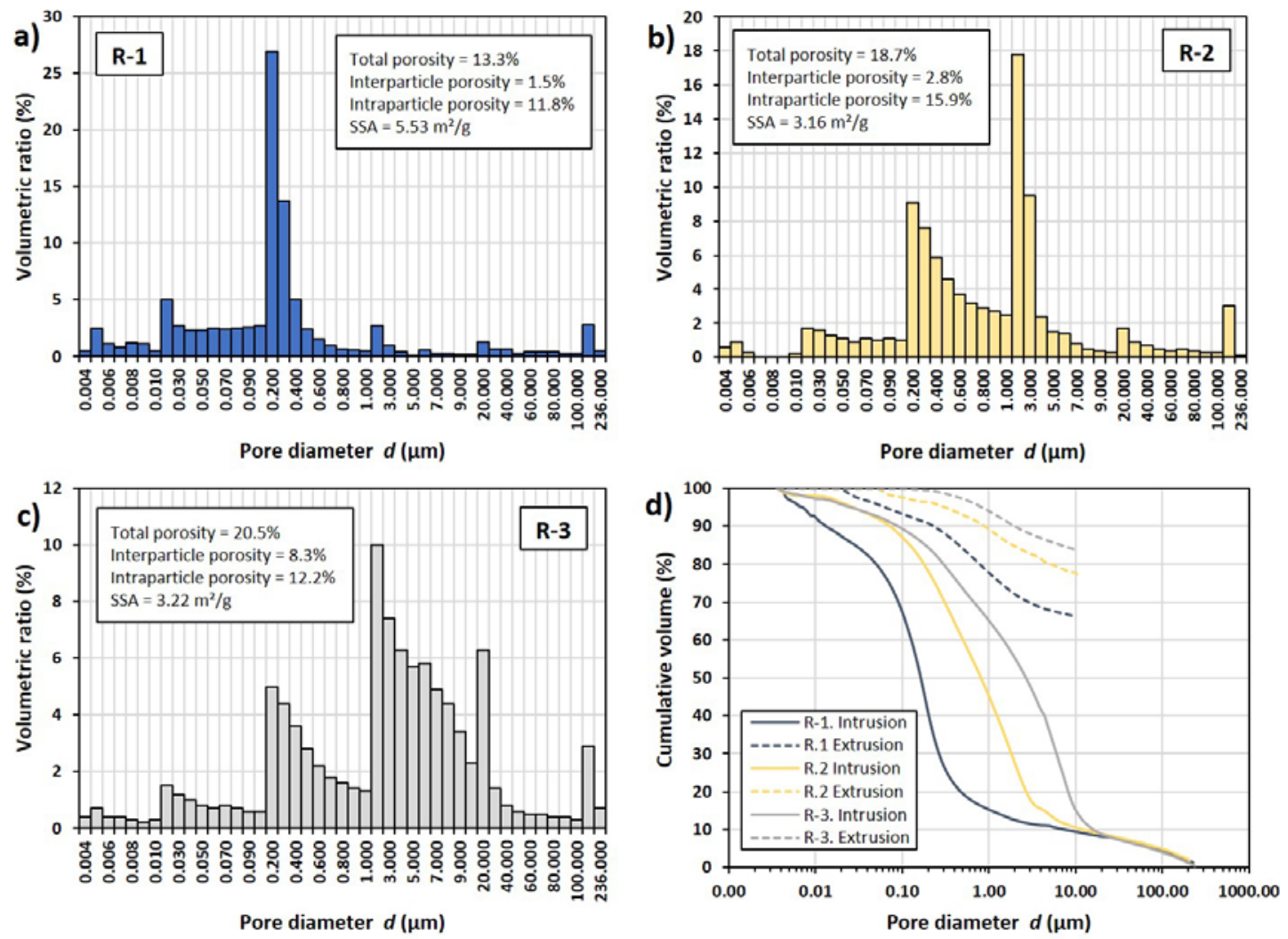

Fig. 5. Variation of volumetric ratio of intruded mercury with the pore-size distribution of R-1 (a), R-2 (b) and R-3 (c) and variation of cumulative volume of intruded and extruded mercury with pore diameter for the three tested stones (d).

\subsection{Triaxial compression tests}

Axial stress-axial strain curve for the different confining pressures obtained in the three tested building stones in both dry and saturated conditions are depicted in Fig. 6. 
This article can be cited as: Rabat, Á., Tomás, R., Cano, M., Miranda, T., 2020. Impact of Water on Peak and Residual Shear Strength Parameters and Triaxial Deformability of High-Porosity Building Calcarenite Stones: Interconnection with their Physical and Petrological Characteristics. Constr. Build. Mater. 262, 120789. https://doi.org/10.1016/j.conbuildmat.2020.120789.
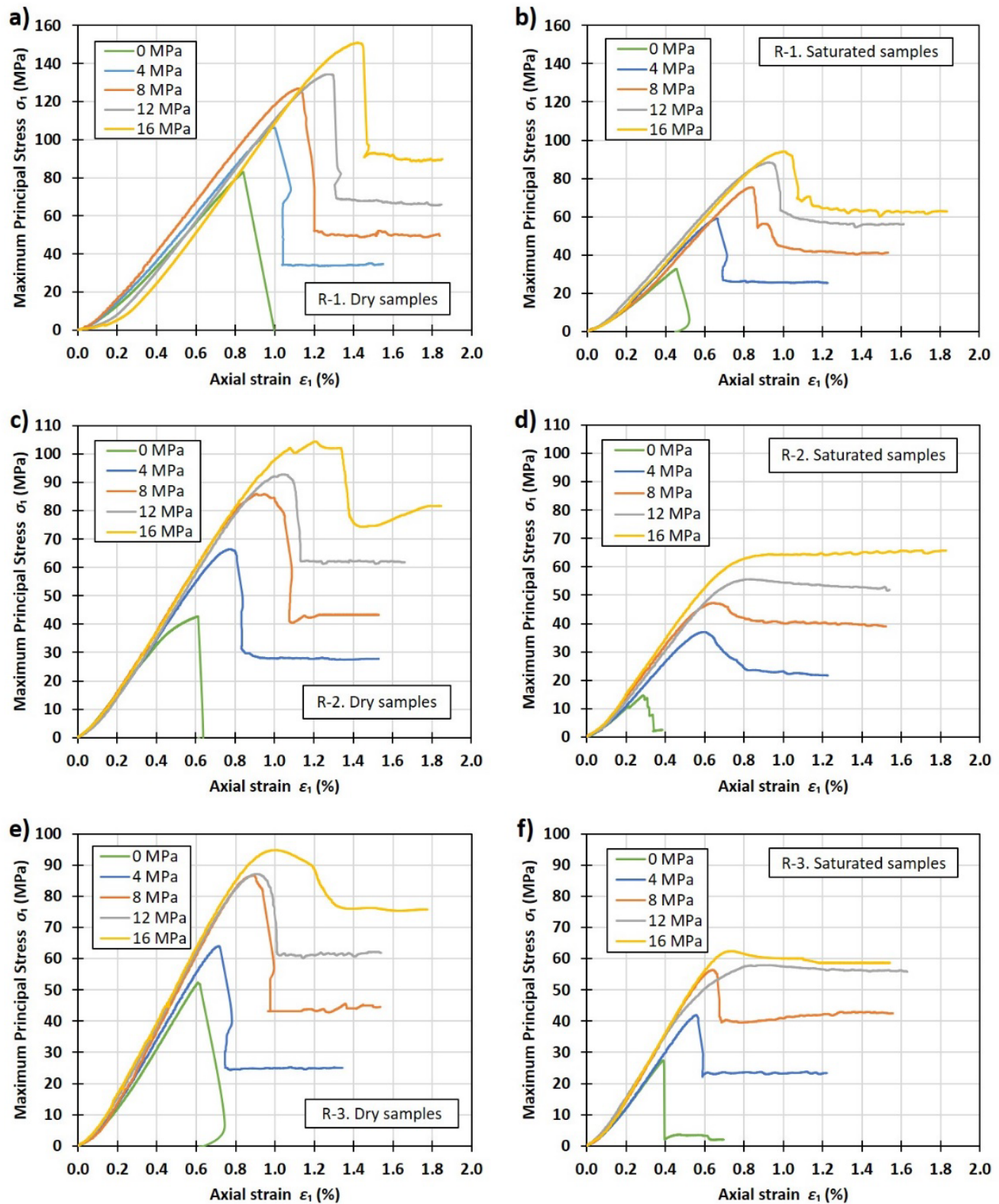

Fig. 6. Axial stress-axial strain curves for the different confining pressures (0, 4, 8, 12 and $16 \mathrm{MPa}$ ) obtained in R-1, R-2 and R-3 under dry ( $a, c$ and e) and saturated (b, d and f) conditions.

Concerning peak compressive strength $\left(\sigma_{\text {peak }}\right)$, in dry state, the highest values were obtained in R-1 (83.0150.8 MPa), while similar values were found in R-2 and R-3 (42.7-104.4 MPa and 52.4-94.7 MPa, respectively). In saturated conditions, R1 exhibited the greatest $\sigma_{\text {peak }}$ values (32.7-94.1 MPa), whereas R2 and R-3 showed comparable values each other (14.7-64.4 MPa and 27.4-62.4 MPa).

With respect to residual compressive strength in dry state, the highest values were found in R-1 (0-89.8 $\mathrm{MPa})$, while the smallest were exhibited by $\mathrm{R}-3$ (0-75.9 $\mathrm{MPa}$ ) and intermediate values were found in R-2 (0.0-81.6 MPa). In saturated conditions, the range of $\sigma_{\text {res }}$ values obtained were 0-62.8, 2.5-64.2 and 2.058.6 MPa in R-1, R-2 and R-3, respectively. Furthermore, despite that, strictly speaking, the residual strength of rocks should be purely "frictional" in nature (i.e., zero residual strength under unconfined conditions) [51], non-zero uniaxial residual strength values were obtained in saturated specimens of R-2 
This article can be cited as: Rabat, Á., Tomás, R., Cano, M., Miranda, T., 2020. Impact of Water on Peak and Residual Shear Strength Parameters and Triaxial Deformability of High-Porosity Building Calcarenite Stones: Interconnection with their Physical and Petrological Characteristics. Constr. Build. Mater. 262, 120789. https://doi.org/10.1016/j.conbuildmat.2020.120789.

and R-3. This may indicate that water could provide a small residual cohesion. Nevertheless, other researchers have reported the presence of non-zero unconfined residual strength values in dry specimens [52], [53] and, therefore, future research would be necessary on this issue.

Regarding the tangent Young's modulus $\left(E_{\mathrm{t}}\right)$, in dry conditions, the greatest values were found in R-1 (12.715.2 GPa) and the lowest values were obtained in R-2 (8.7-12.5 GPa). Intermediate values were exhibited by R-3 (10.2-13.1 GPa). In saturated conditions the same hierarchical order remained, particularly, the ranges of the $E_{\mathrm{t}}$ values found were 8.3-14.2, 6.4-9.8 and 8.1-10.7 GPa in R-1, R-2 and R-3, respectively.

The greater values of $\sigma_{\text {peak, }} \sigma_{\text {res }}$ and $E_{\mathrm{t}}$ obtained in R-1 in both conditions (dry and saturated states) may be explained by its lower porosity and higher density and P-wave velocity in comparison with R-2 and R-3, which exhibit similar mechanical behaviour and physical characteristics. In this sense, several authors have proposed increasing exponential or power correlation functions between physical properties (such as $\rho$ dry and $V_{P}$ ) and mechanical properties (UCS and $E_{t}$ ) as well as decreasing potential correlation functions between $\mathrm{p}$ and UCS (or $E_{\mathrm{t}}$ ) for sedimentary rock materials such as sandstones, travertines and calcarenites [20], [32], [54], [55]. The triaxial testing data of each building stone in dry and saturated conditions are summarized in Table 2.

Table 2. Triaxial testing data of tested building stones in dry and saturated conditions. *Value obtained in the specimen reserved to check the reproducibility of triaxial tests.

\begin{tabular}{|c|c|c|c|c|c|c|}
\hline $\begin{array}{l}\text { Stone ID } \\
\text { (moisture } \\
\text { condition) }\end{array}$ & $\begin{array}{l}\text { Confining } \\
\text { pressures } \sigma_{3} \\
(\mathrm{MPa})\end{array}$ & $\begin{array}{c}\text { Peak strength } \\
\sigma_{\text {peak }}(\mathrm{MPa})\end{array}$ & $\begin{array}{l}\text { Residual } \\
\text { strength } \sigma_{\text {res }} \\
(\mathrm{MPa})\end{array}$ & $\begin{array}{l}\text { Axial strain } \\
\text { at failure } \\
\varepsilon_{\text {peak }}\left(10^{-6}\right)\end{array}$ & $\begin{array}{c}\text { Shear band } \\
\text { orientation } \\
\qquad \beta\left(^{\circ}\right)\end{array}$ & $\begin{array}{c}\text { Tangent } \\
\text { Young's } \\
\text { modulus } E_{\mathrm{t}} \\
\text { (GPa) }\end{array}$ \\
\hline \multirow{5}{*}{$\begin{array}{l}\text { R-1 } \\
\text { (dry) }\end{array}$} & 0 & 83.0 & 0.0 & 8408 & 71.1 & 12.7 \\
\hline & 4 & 106.3 & 34.7 & 9910 & 67.3 & 13.4 \\
\hline & 8 & 126.9 & 49.5 & 11195 & 62.6 & 13.8 \\
\hline & 12 & 134.3 & 65.9 & 12675 & 61.9 & 14.3 \\
\hline & 16 & $150.8-151.7^{*}$ & 89.8 - $90.3^{*}$ & 14174 & 58.9 & 15.2 \\
\hline \multirow{5}{*}{$\begin{array}{c}\mathrm{R}-1 \\
\text { (saturated) }\end{array}$} & 0 & 32.7 & 0.0 & 4533 & 66.3 & 8.3 \\
\hline & 4 & 59.0 & 25.4 & 6621 & 62.5 & 12.1 \\
\hline & 8 & 75.4 & 41.2 & 8365 & 60.3 & 13.1 \\
\hline & 12 & 88.4 & 56.2 & 9203 & 59.3 & 12.0 \\
\hline & 16 & 94.1 & 62.8 & 10061 & 58.6 & 14.2 \\
\hline \multirow{5}{*}{$\begin{array}{l}\mathrm{R}-2 \\
\text { (dry) }\end{array}$} & 0 & 42.7 & 0.0 & 6117 & 72.0 & 8.7 \\
\hline & 4 & 66.4 & 27.8 & 7733 & 63.4 & 10.2 \\
\hline & 8 & 85.9 & 43.3 & 9052 & 64.1 & 10.6 \\
\hline & 12 & 92.8 & 61.2 & 10501 & 59.6 & 10.4 \\
\hline & 16 & 104.4 - 103.9* & 81.6 - 81.4* & 12074 & 58.2 & 12.5 \\
\hline \multirow{5}{*}{$\begin{array}{c}\mathrm{R}-2 \\
\text { (saturated) }\end{array}$} & 0 & 14.7 & 2.5 & 2888 & 71.8 & 6.4 \\
\hline & 4 & 37.0 & 21.7 & 5996 & 62.4 & 7.3 \\
\hline & 8 & 47.3 & 39.0 & 6456 & 59.4 & 8.1 \\
\hline & 12 & 55.6 & 51.9 & 8365 & 59.2 & 8.9 \\
\hline & 16 & 64.4 & 64.2 & 9265 & 57.6 & 9.8 \\
\hline \multirow{4}{*}{$\begin{array}{l}\text { R-3 } \\
\text { (dry) }\end{array}$} & 0 & 52.4 & 0.0 & 6089 & 68.1 & 10.2 \\
\hline & 4 & 64.0 & 25.0 & 7149 & 67.3 & 10.7 \\
\hline & 8 & 86.6 & 44.6 & 8887 & 63.2 & 12.9 \\
\hline & 12 & 87.1 & 61.8 & 9093 & 59.3 & 12.5 \\
\hline
\end{tabular}


This article can be cited as: Rabat, Á., Tomás, R., Cano, M., Miranda, T., 2020. Impact of Water on Peak and Residual Shear Strength Parameters and Triaxial Deformability of High-Porosity Building Calcarenite Stones: Interconnection with their Physical and Petrological Characteristics. Constr. Build. Mater. 262, 120789. https://doi.org/10.1016/j.conbuildmat.2020.120789.

\begin{tabular}{|c|c|c|c|c|c|c|}
\hline & 16 & $94.7-94.3^{*}$ & $75.9-76.2^{*}$ & 10061 & 58.4 & 13.1 \\
\hline \multirow{4}{*}{$\begin{array}{c}\text { R-3 } \\
\text { (saturated) }\end{array}$} & 0 & 27.4 & 2.0 & 3896 & 78.1 & 8.1 \\
\cline { 2 - 7 } & 4 & 41.9 & 23.3 & 5577 & 62.6 & 8.9 \\
\cline { 2 - 7 } & 8 & 56.4 & 42.5 & 6415 & 56.8 & 10.1 \\
\cline { 2 - 7 } & 12 & 57.8 & 55.8 & 8365 & 56.1 & 10.3 \\
\hline
\end{tabular}

\subsection{Failure envelopes using Mohr-Coulomb, Hoek-Brown and Cohesion-Loss models}

The relationships between the confining pressure and the peak and residual compressive strength values of the tested building stones in dry and saturated conditions as well as the failure envelopes obtained using Mohr-Coulomb, Hoek-Brown and Cohesion Loss models are shown in Fig. 7. 
This article can be cited as: Rabat, Á., Tomás, R., Cano, M., Miranda, T., 2020. Impact of Water on Peak and Residual Shear Strength Parameters and Triaxial Deformability of High-Porosity Building Calcarenite Stones: Interconnection with their Physical and Petrological Characteristics. Constr. Build. Mater. 262, 120789. https://doi.org/10.1016/j.conbuildmat.2020.120789.
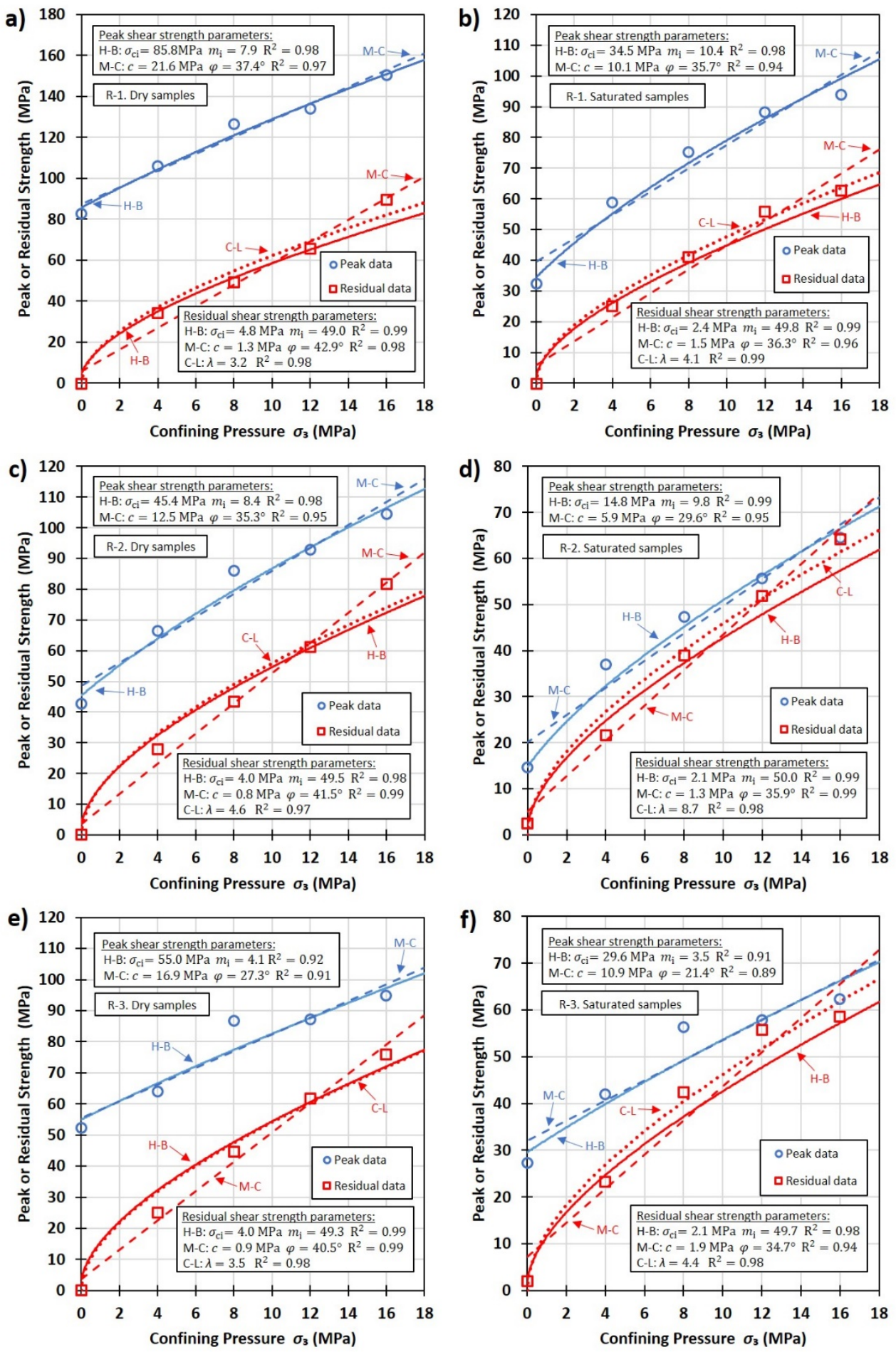

Fig. 7. Variation of peak and residual compressive strength with the confining pressure in dry ( $a, c$ and e) and saturated (b, $d$ and e) conditions and the corresponding Mohr-Coulomb (M-C), Hoek-Brown (H-B) and Cohesion-loss (C-L) failure envelopes for the three tested materials.

Regarding the Mohr-Coulomb peak shear strength parameters, in dry conditions, the highest peak cohesion $\left(c_{\text {peak }}\right)$ and internal friction angle $\left(\phi_{\text {peak }}\right)$ were obtained in R-1 (21.6 MPa and $37.4^{\circ}$, respectively). For its part, R-2 exhibited a lower $c_{\text {peak }}$ and a greater $\phi_{\text {peak }}\left(12.5 \mathrm{MPa}\right.$ and $35.3^{\circ}$, respectively) than R-3 
This article can be cited as: Rabat, Á., Tomás, R., Cano, M., Miranda, T., 2020. Impact of Water on Peak and Residual Shear Strength Parameters and Triaxial Deformability of High-Porosity Building Calcarenite Stones: Interconnection with their Physical and Petrological Characteristics. Constr. Build. Mater. 262, 120789. https://doi.org/10.1016/j.conbuildmat.2020.120789.

(16.9 $\mathrm{MPa}$ and $27.3^{\circ}$, respectively). In the same vein, in saturated conditions, the greatest $c_{\text {peak }}$ and $\phi_{\text {peak }}$ values were found in R-1 (10.1 MPa and 35.7, respectively), while R-2 showed a smaller $c_{\text {peak }}$ and a higher $\phi_{\text {peak }}\left(5.9 \mathrm{MPa}\right.$ and $29.6^{\circ}$, respectively) than R-3 (10.9 MPa and $21.4^{\circ}$, respectively). The highest values of $C_{\text {peak }}$ and $\phi_{\text {peak }}$ obtained in R-1 in both conditions (dry and saturated states) could be attributed to its lower porosity and higher density and wave velocities in comparison with R-2 and R-3. Furthermore, according to Plumb [56], the fact that R-3 displays a much lower $\phi_{\text {peak }}$ than R-2 in both conditions can be explained by its higher clay mineral content and porosity.

With regard to residual shear strength parameters, the obtained residual cohesion (cres) values were very low in the three stone types in both dry and saturated states (they ranged from 0.8 to $1.9 \mathrm{MPa}$ ) while the obtained residual friction angle $\left(\phi_{\text {res }}\right)$ values were moderately high in both dry and saturated conditions (they ranged from 34.7 to $42.9^{\circ}$ ). All peak and residual shear strength parameters of the tested stones obtained by Mohr-Coulomb criterion are reflected in Table 3.

Comparing peak with residual shear strength parameters obtained through Mohr-Coulomb criterion, it can be observed that $c_{\text {peak }}$ values were much higher than $c_{\text {res }}$ values, while $\phi_{\text {peak }}$ values were smaller than $\phi_{\text {res }}$ values in the three stones and for both dry and saturated conditions. These findings indicate that the failure of the three calcarenite materials is related with a reduction of the cohesion and an increase of friction angle and that, therefore, the obtained results could be successfully fitted through the cohesion weakening and friction strengthening (CWFS) Mohr-Coulomb model proposed by Hajiabdolmajid et al. [57] or the cohesion loss model proposed by Peng and Cai [41].

Table 3. Cohesion and friction angle of peak and residual values of the tested building stones in dry and saturated conditions obtained through the Mohr-Coulomb criterion.

\begin{tabular}{|c|c|c|c|c|c|c|c|c|c|c|}
\hline & \multicolumn{5}{|c|}{$\begin{array}{c}\text { Peak shear strength } \\
\text { Parameters (M-C criterion) }\end{array}$} & \multicolumn{5}{|c|}{$\begin{array}{c}\text { Residual shear strength } \\
\text { Parameters (M-C criterion) }\end{array}$} \\
\hline $\begin{array}{c}\text { Stone ID } \\
\text { (moisture condition) }\end{array}$ & $\begin{array}{l}c_{\text {peak }} \\
(\mathrm{MPa})\end{array}$ & $\begin{array}{c}\varphi_{\text {peak }} \\
\left(^{\circ}\right)\end{array}$ & $\mathrm{R}^{2}$ & $\begin{array}{l}c_{\text {peak }}^{\text {sat }} \\
c_{\text {peak }}^{\text {dry }} \\
\end{array}$ & $\frac{\varphi_{\text {peak }}^{\text {sat }}}{\varphi_{\text {peak }}^{\text {dry }}}$ & $\begin{array}{c}c_{\text {res }} \\
(\mathrm{MPa})\end{array}$ & $\begin{array}{c}\varphi_{\text {res }} \\
\left(^{\circ}\right)\end{array}$ & $\mathrm{R}^{2}$ & $\frac{c_{\text {res }}^{\text {sat }}}{c_{\text {res }}^{\text {dry }}}$ & $\frac{\varphi_{\text {res }}^{\text {sat }}}{\varphi_{\text {res }}^{\text {dry }}}$ \\
\hline $\begin{array}{c}\text { R-1 } \\
\text { (dry) }\end{array}$ & 21.6 & 37.4 & 0.97 & \multirow{2}{*}{0.47} & \multirow{2}{*}{0.95} & 1.3 & 42.9 & 0.98 & \multirow{2}{*}{1.16} & \multirow{2}{*}{0.85} \\
\hline $\begin{array}{c}\text { R-1 } \\
\text { (saturated) }\end{array}$ & 10.1 & 35.7 & 0.94 & & & 1.5 & 36.3 & 0.96 & & \\
\hline $\begin{array}{c}\mathrm{R}-2 \\
\text { (dry) }\end{array}$ & 12.5 & 35.3 & 0.95 & \multirow{2}{*}{0.47} & \multirow{2}{*}{0.84} & 0.8 & 41.5 & 0.99 & \multirow{2}{*}{1.68} & \multirow{2}{*}{0.87} \\
\hline $\begin{array}{c}\mathrm{R}-2 \\
\text { (saturated) }\end{array}$ & 5.9 & 29.6 & 0.95 & & & 1.3 & 35.9 & 0.99 & & \\
\hline $\begin{array}{c}\text { R-3 } \\
\text { (dry) }\end{array}$ & 16.9 & 27.3 & 0.91 & \multirow{2}{*}{0.65} & \multirow{2}{*}{0.78} & 0.9 & 40.5 & 0.99 & \multirow{2}{*}{2.21} & \multirow{2}{*}{0.86} \\
\hline $\begin{array}{c}\mathrm{R}-3 \\
\text { (saturated) }\end{array}$ & 10.9 & 21.4 & 0.89 & & & 1.9 & 34.7 & 0.94 & & \\
\hline
\end{tabular}

With regard to the Hoek-Brown peak shear strength parameters, in dry conditions, the highest peak unconfined compressive strength ( $\sigma_{\text {cipeak }}$ ) value was obtained in R-1 (85.8 MPa) while quite similar values were found in R-2 and R-3 (45.4 and 55.0 MPa, respectively). Conversely, the greatest peak Hoek-Brown constant ( $m_{\text {ipeak }}$ ) value was obtained in R-2 (8.4) and the lowest value was found in R-3 (4.1), while an intermediate value was exhibited by $\mathrm{R}-1$ (7.9). In saturated conditions, the $\sigma_{\text {cipeak }}$ and $m$ ipeak values found in R-1 were 34.5 MPa and 10.4, respectively, whereas the obtained values in R-2 (14.8 MPa and 9.8, respectively) and R-3 (29.6 MPa and 3.5, respectively) were considerably smaller. The larger values of 
This article can be cited as: Rabat, Á., Tomás, R., Cano, M., Miranda, T., 2020. Impact of Water on Peak and Residual Shear Strength Parameters and Triaxial Deformability of High-Porosity Building Calcarenite Stones: Interconnection with their Physical and Petrological Characteristics. Constr. Build. Mater. 262, 120789. https://doi.org/10.1016/j.conbuildmat.2020.120789.

$\sigma_{\text {cipeak }}$ obtained in R-1 in dry and saturated conditions can be explained by its smaller porosity and higher density and P-wave velocity in comparison with R-2 and R-3. Furthermore, the fact that R-3 shows a much smaller $m_{\text {ipeak }}$ than the other calcarenite types in both dry and saturated conditions can be explained by its greater porosity and phyllosilicate content, that is the same reason which justifies its smaller $\phi_{\text {peak }}\left(m_{\mathrm{b}}\right.$ is analogous to the frictional strength component in the Mohr-Coulomb model [43]).

Concerning the residual shear strength parameters, the highest residual unconfined compressive strength ( $\sigma_{\text {cires }}$ ) values were found in R-1 (4.8 and 2.4 MPa in dry and saturated conditions, respectively) and the lowest values were obtained in R-3 (4.0 and 2.1 MPa in dry and saturated conditions, respectively). The values obtained in R-2 were very close to the values of R-3. By contrast, the residual Hoek-Brown constant ( $\left.m_{\text {ires }}\right)$ values obtained in the three building stone types in both dry and saturated states were very similar each other. Additionally, comparing peak with residual shear strength parameters obtained through Hoek-Brown criterion, it can be observed that $\sigma_{\text {cipeak }}$ values were much higher than $\sigma_{\text {cires }}$ values. Contrarily, $m_{\text {ipeak }}$ values were lower than $m_{\text {ires }}$ values in the three stones for both dry and saturated conditions.

With respect to the dimensionless parameter $\lambda$ of the Cohesion-Loss model, which was calculated from the residual strength data, the highest values in both dry and saturated conditions were found in R-2 (4.6 and 8.7, respectively) and the smallest values were obtained in R-1 (3.2 and 4.1, respectively). For its part, R-3 exhibit values closer to R-1 (3.5 and 4.4, respectively). The biggest values of $\lambda$ found in R-2 in comparison with the other varieties are related to its more ductile behaviour for higher confining pressures (especially, in saturated conditions). Similar values of $\lambda$ were found by Peng and Cai [41] in sandstones, limestones and marbles after using this model to fit several triaxial datasets collected from literature.

All shear strength parameters of tested building materials obtained by Hoek-Brown criterion and Cohesion-Loss model are shown in Table 4.

Table 4. $\sigma_{\mathrm{ci}}$ and $\mathrm{m}_{\mathrm{i}}$ of peak and residual values obtained through the Hoek-Brown criterion and $\lambda$ of residual values obtained through the Cohesion-Loss model of the tested building stones in dry and saturated conditions.

\begin{tabular}{|c|c|c|c|c|c|c|c|c|c|c|c|c|c|}
\hline \multirow[b]{3}{*}{$\begin{array}{l}\text { Stone ID } \\
\text { (moisture } \\
\text { condition) }\end{array}$} & \multirow{2}{*}{\multicolumn{5}{|c|}{$\begin{array}{c}\text { Peak shear strength parameters } \\
\text { (H-B criterion) }\end{array}$}} & \multicolumn{8}{|c|}{ Residual shear strength parameters } \\
\hline & & & & & & \multicolumn{5}{|c|}{ (H-B criterion) } & \multicolumn{3}{|c|}{ (C-L model) } \\
\hline & $\begin{array}{l}\sigma_{\text {cipeak }} \\
(\mathrm{MPa})\end{array}$ & $m_{\text {ipeak }}$ & $\mathrm{R}^{2}$ & $\frac{\sigma_{\text {cipeak }}^{\text {sat }}}{\sigma_{\text {cipeak }}^{\text {dry }}}$ & $\frac{m_{\text {ipeak }}^{\text {sat }}}{m_{\text {ipeak }}^{\text {dry }}}$ & $\begin{array}{c}\sigma_{\text {cres }} \\
(\mathrm{MPa})\end{array}$ & $m_{\text {ires }}$ & $\mathrm{R}^{2}$ & $\frac{\sigma_{\text {cires }}^{\text {sat }}}{\sigma_{\text {cires }}^{\text {dry }}}$ & $\frac{m_{\text {ires }}^{\text {sat }}}{m_{\text {ires }}^{\text {dry }}}$ & $\lambda$ & $R^{2}$ & $\frac{\lambda^{\text {sat }}}{\lambda^{d r y}}$ \\
\hline $\begin{array}{c}\mathrm{R}-1 \\
\text { (dry) }\end{array}$ & 85.8 & 7.9 & 0.98 & \multirow{2}{*}{0.40} & \multirow{2}{*}{1.32} & 4.8 & 49.0 & 0.98 & \multirow{2}{*}{0.51} & \multirow{2}{*}{1.02} & 3.2 & 0.98 & \multirow{2}{*}{1.3} \\
\hline $\begin{array}{c}\mathrm{R}-1 \\
\text { (saturated) } \\
\end{array}$ & 34.5 & 10.4 & 0.98 & & & 2.4 & 49.8 & 0.99 & & & 4.1 & 0.99 & \\
\hline $\begin{array}{c}\mathrm{R}-2 \\
\text { (dry) }\end{array}$ & 45.4 & 8.4 & 0.98 & \multirow{2}{*}{0.33} & \multirow{2}{*}{1.16} & 4.0 & 49.5 & 0.98 & \multirow{2}{*}{0.54} & \multirow{2}{*}{1.01} & 4.6 & 0.97 & \multirow{2}{*}{1.9} \\
\hline $\begin{array}{c}\mathrm{R}-2 \\
\text { (saturated) }\end{array}$ & 14.8 & 9.8 & 0.99 & & & 2.1 & 50.0 & 0.99 & & & 8.7 & 0.98 & \\
\hline $\begin{array}{c}\text { R-3 } \\
\text { (dry) } \\
\end{array}$ & 55.0 & 4.1 & 0.92 & \multirow{2}{*}{0.54} & \multirow{2}{*}{0.86} & 4.0 & 49.3 & 0.99 & \multirow{2}{*}{0.54} & \multirow{2}{*}{1.01} & 3.5 & 0.98 & \multirow{2}{*}{1.3} \\
\hline $\begin{array}{c}\mathrm{R}-3 \\
\text { (saturated) }\end{array}$ & 29.6 & 3.5 & 0.91 & & & 2.1 & 49.7 & 0.98 & & & 4.4 & 0.98 & \\
\hline
\end{tabular}


This article can be cited as: Rabat, Á., Tomás, R., Cano, M., Miranda, T., 2020. Impact of Water on Peak and Residual Shear Strength Parameters and Triaxial Deformability of High-Porosity Building Calcarenite Stones: Interconnection with their Physical and Petrological Characteristics. Constr. Build. Mater. 262, 120789. https://doi.org/10.1016/j.conbuildmat.2020.120789.

\subsection{Failure pattern of samples}

Failure pattern of dry and saturated tested building stones are depicted in Fig. 8. In the three materials and in both dry and saturated conditions, spalling and tensile cracks can be recognized under uniaxial compression. When the confining pressure increased to $4 \mathrm{MPa}$, in some dry specimens few axial tensile cracks appeared along the shear plane and afterwards tensile crack evolved towards to a macroscopic failure surface. However, in saturated samples and in some dry samples can also be seen a principal shear plane passing through the total length of specimens for confining pressures of $4 \mathrm{MPa}$. Under higher confining pressures (i.e. 8,12 and $16 \mathrm{MPa}$ ) in both dry and saturated conditions, the vast majority of specimens were mainly cut into two pieces through a single shear plane. Notwithstanding, in some cases saturated specimens exhibited more than one macro-fracture while dry specimens always showed only one, indicating that the failure characteristics of saturated samples were less severe. Furthermore, as would be expected, it was noted that the angle of shear plane with respect to the minor principal stress $(\beta)$ decreases with the confining pressure.

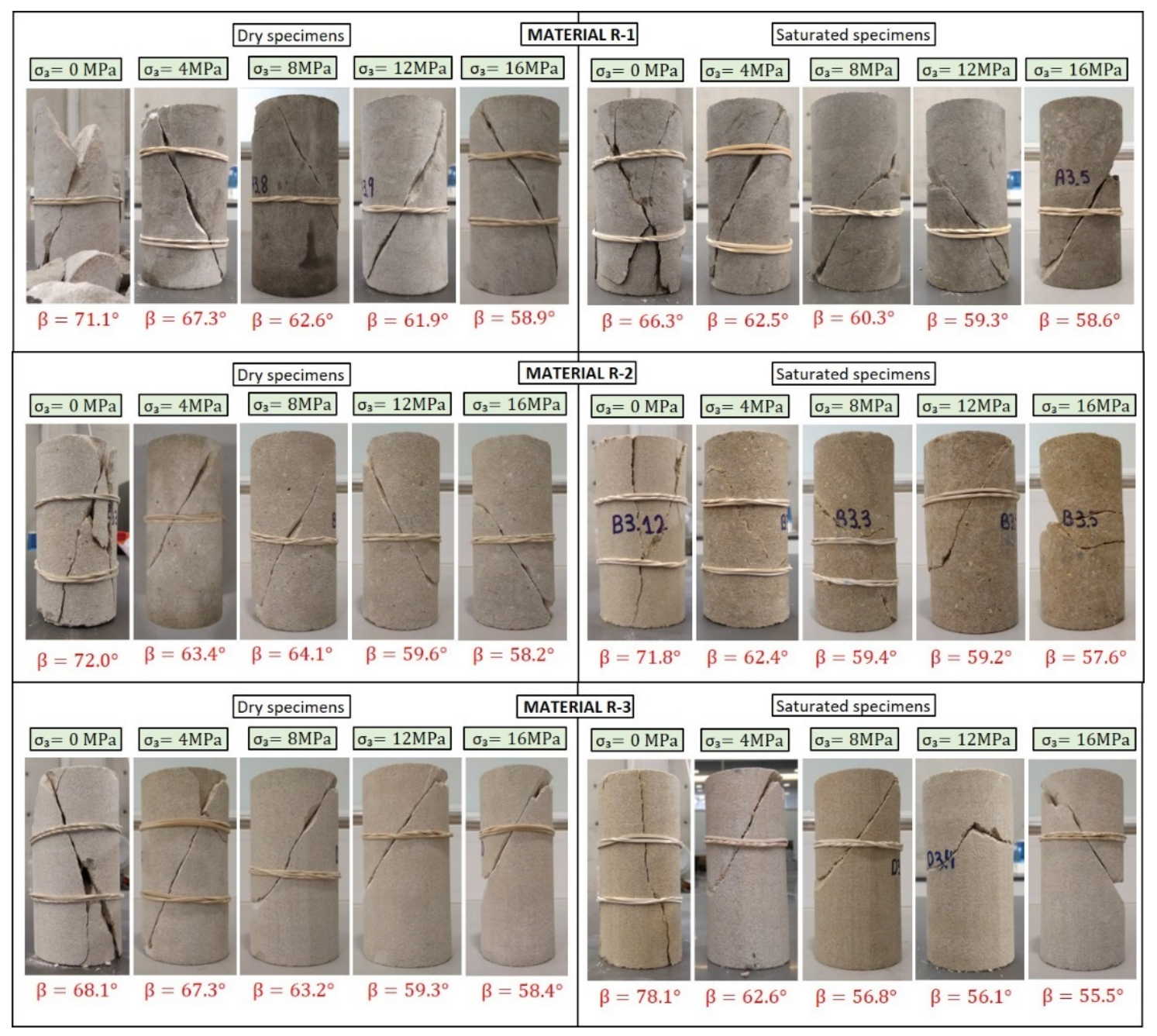


This article can be cited as: Rabat, Á., Tomás, R., Cano, M., Miranda, T., 2020. Impact of Water on Peak and Residual Shear Strength Parameters and Triaxial Deformability of High-Porosity Building Calcarenite Stones: Interconnection with their Physical and Petrological Characteristics. Constr. Build. Mater. 262, 120789. https://doi.org/10.1016/j.conbuildmat.2020.120789.

Fig. 8. Failure patterns of dry and saturated specimens of the three building stones. $\beta$ : angle of shear plane with respect to the minor principal stress.

\subsection{Influence of confining pressure on peak and residual compressive strength, tangent Young's modulus and shear band orientation}

The axial strain-axial stress plots for the entire range of confining pressures (Fig. 6) indicate that initially the stress-strain relation shows a small nonlinear deformation which could be attributed to the closure of microcracks. Then, it can observe the typical elastic behaviour which is followed by inelastic yield (at 0.60.8 of peak stress approximately) and temporary strain hardening in all dry stones. This behaviour is also observed for all the saturated specimens of R-1 and for the saturated specimens of R-2 and R-3 subjected to low confining pressures (4-8 MPa). However, the saturated specimens of R-2 and R-3 subjected to high confining pressures (12 and $16 \mathrm{MPa}$ ) exhibit a continuous strain hardening. Generally, the value of peak stress consistently increases in agreement with confining pressure, and, after failure, specimens subjected to confining pressure deform at a constant stress value which is function of the confining pressure. This behaviour is similar to those reported by Yang et al. [58], Mair et al. [25] and Heap et al. [59] in different types of sandstones.

Therefore, it can be appreciated that while the three tested stone types exhibited a brittle behaviour in dry conditions, the saturated specimens of R-2 and R-3 stones showed a transitional behaviour (from brittle to ductile) for the confining pressures values of 12 and $16 \mathrm{MPa}$, that is, the difference between peak and residual strength significantly decreases or even completely disappears. This finding can be attributed to the fact that R-2 and R-3 are more porous and weaker calcarenites than R- 1 and, as a consequence, the corresponding confining pressure required to exhibit a change from brittle to ductile regime is lower. Similar findings were obtained by Baud et al. [3] for sandstones.

The variation of $E_{\mathrm{t}}$ with the confining pressure for the three tested building materials in both dry and saturated conditions are depicted in Fig. 9. In general, $E_{\mathrm{t}}$ increases significantly with confining pressure. Similar results were found by Li et al. [60] in sandstones and by Li et al. [29] in meta-sedimentary rocks. Specifically, in dry conditions, when the confining pressure increases from 0 to $16 \mathrm{MPa}$, $E_{\mathrm{t}}$ rises by 19.7, 43.7 and $28.4 \%$ in R-1, R-2 and R-3, respectively. Furthermore, in saturated conditions, these increases are higher. More specifically, $E_{\mathrm{t}}$ rises by $71.1 \%$ in $\mathrm{R}-1,53.1 \%$ in $\mathrm{R}-2$ and $32.1 \%$ in $\mathrm{R}-3$ when the confining pressure increases from 0 to $16 \mathrm{MPa}$.

The relationships between the confining pressure and the shear band orientation for the three tested building stones in both dry and saturated states are shown in Fig. 9. The results indicate that the angle of shear band with respect to the minor principal stress $(\beta)$ decreases with the confining pressure. (i.e. the angle of shear band with respect to the major principal strength increases with the confining pressure). In particular, in dry conditions, when the confining pressure increases from 0 to $16 \mathrm{MPa}, \beta$ decreases from $71^{\circ}$ to $59^{\circ}$ in R- 1 , from $72^{\circ}$ to $58^{\circ}$ in R-2 and from $68^{\circ}$ to $58^{\circ}$ in R-3. Similarly, in saturated conditions, $\beta$ reduces from $66^{\circ}$ to $59^{\circ}$ in $\mathrm{R}-1$, from $72^{\circ}$ to $58^{\circ}$ in $\mathrm{R}-2$ and from $78^{\circ}$ to $56^{\circ}$ in $\mathrm{R}-3$ when the confining pressures increases from 0 to $16 \mathrm{MPa}$. These findings are in accordance with the results obtained by Wasantha and Ranjith [9] in Hawkesbury sandstone. These authors observed that $\beta$ ranged from 55 to $45^{\circ}$ in dry samples and from 50 to $40^{\circ}$ in saturated samples when confining pressure varied from 4 to $25 \mathrm{MPa}$. 
This article can be cited as: Rabat, Á., Tomás, R., Cano, M., Miranda, T., 2020. Impact of Water on Peak and Residual Shear Strength Parameters and Triaxial Deformability of High-Porosity Building Calcarenite Stones: Interconnection with their Physical and Petrological Characteristics. Constr. Build. Mater. 262, 120789. https://doi.org/10.1016/j.conbuildmat.2020.120789.

Furthermore, similar results were also found by Bésuelle et al. [30], Mair et al. [25] and Sulem and Ouffroukh [31] in other types of sandstone and by Arzúa and Alejano [52] in granites.

a)

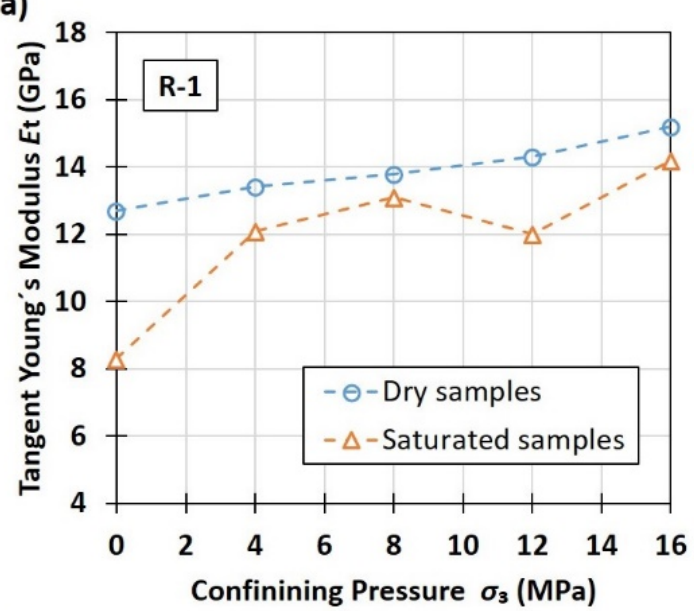

b)

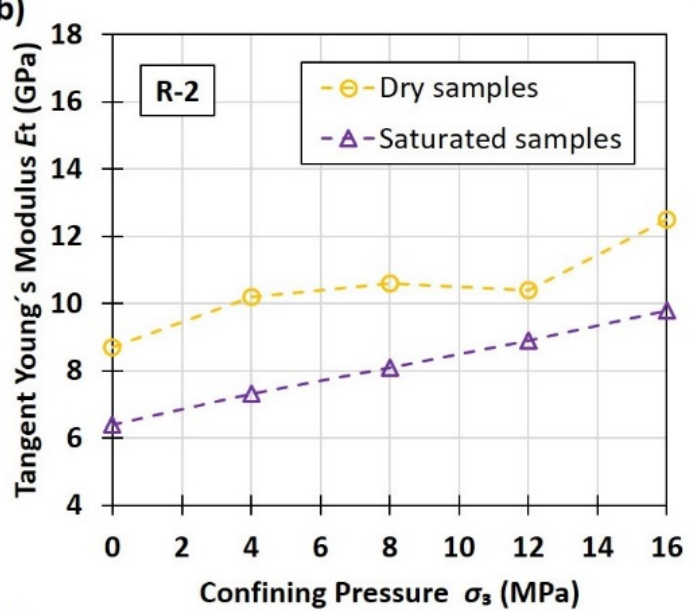

c)

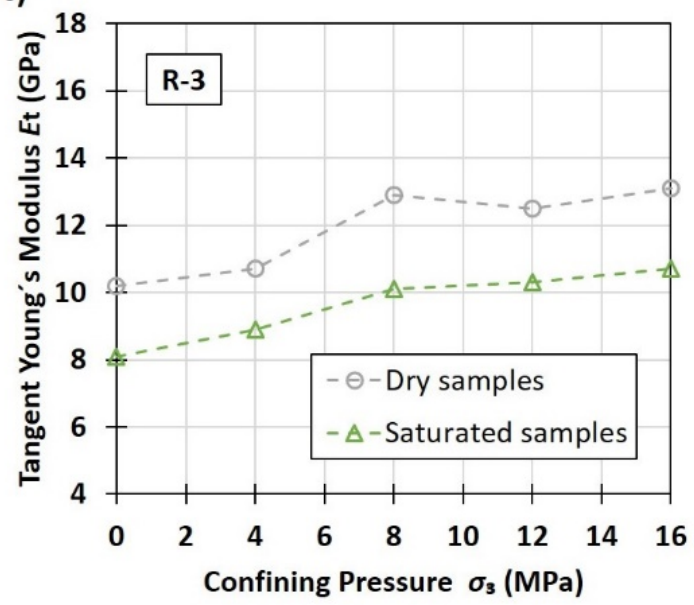

d)

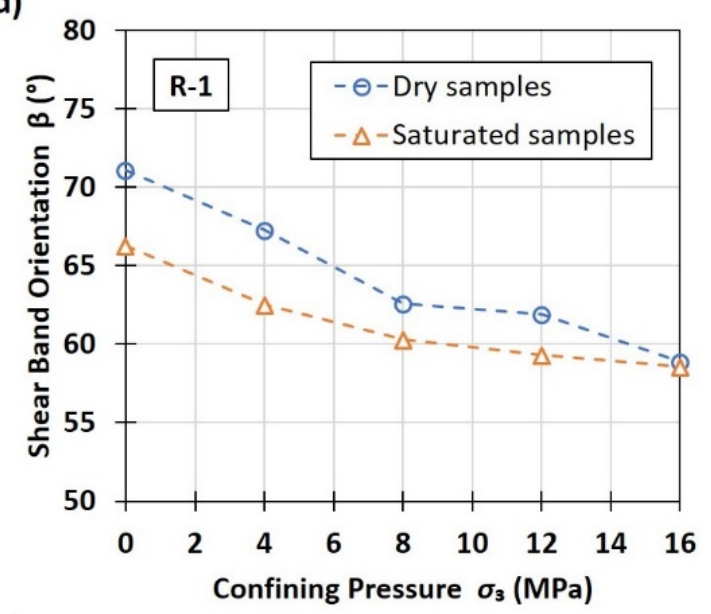

e)

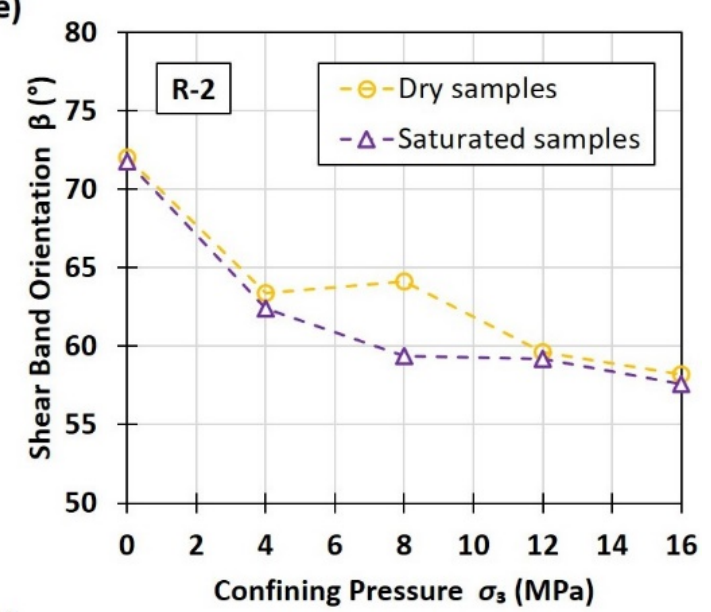

f)

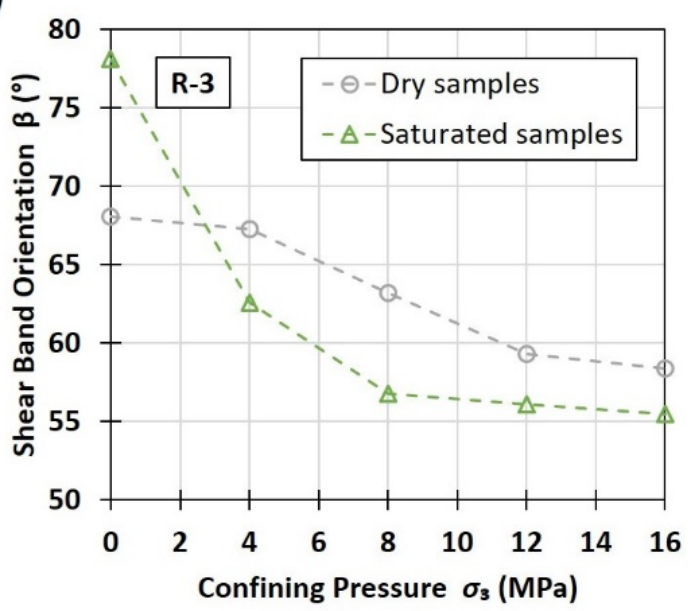

Fig. 9. Variation of tangent Young's modulus $(a, b$ and $c)$ and shear band orientation $(\beta)(d, e$ and $f)$ with the confining pressure in the three tested building materials under dry and saturated conditions.

\section{DISCUSSION}


This article can be cited as: Rabat, Á., Tomás, R., Cano, M., Miranda, T., 2020. Impact of Water on Peak and Residual Shear Strength Parameters and Triaxial Deformability of High-Porosity Building Calcarenite Stones: Interconnection with their Physical and Petrological Characteristics. Constr. Build. Mater. 262, 120789. https://doi.org/10.1016/j.conbuildmat.2020.120789.

\subsection{Impact of water on peak and residual compressive strength and tangent Young's modulus}

The impact of water on $\sigma_{\text {peak }}$ for the tested building materials is shown in Fig. 10.a. Very significant reductions of $\sigma_{\text {peak }}$ were found in the three stones due to their water saturation. Specifically, the decreases ranged from $34.2 \%$ to $60.6 \%$ in $\mathrm{R}-1$, from $38.3 \%$ to $65.7 \%$ in $\mathrm{R}-2$ and from $33.6 \%$ to $47.7 \%$ in $\mathrm{R}-3$, depending on the confining pressure.

According to scientific literature, the water-weakening behaviour of geomaterials could be mainly attributed to two different types of mechanisms [9]: (1) physicochemical effects caused by interactions between water and solid constituents of rock materials; and (2) mechanical effects. Based on physical and petrological characteristics of the tested calcarenites and the circumstances in which triaxial tests were performed (undrained conditions), the joint action of both effects was probably responsible for the observed water-weakening behaviour in the three studied calcarenites.

On the one hand, water-weakening effects linked to physicochemical effects are considered to mainly result from subcritical crack phenomena and a decrease of friction coefficient [8], [9]. Subcritical crack growth defines the stable propagation of cracks at values of intensity factors lower than the critical stress intensity and is principally governed by the coupled effects of fracture energy decrease and stress corrosion, in which the water plays a key role promoting stress corrosion in silicate and quartz-rich rocks [8]. In this connection, according to the semiquantitative analyses of $X R D$, the three stone varieties have an important quantity of quartz (5-20\%) and, additionally, R-1 and R-2 have small quantities of calcium silicate, suggesting that stress corrosion may have played a relevant role in the $\sigma_{\text {peak }}$ reductions observed in these varieties. A molecular interpretation of stress corrosion in silica was proposed by Michalske and Freiman [61] and a general expression for $\mathrm{Si}-\mathrm{O}$ bond reacting with $\mathrm{H}_{2} \mathrm{O}$ was offered by Atkinson and Meredith [62], [63], which can be seen in Eq. 6. In summary, the strong Si-O bonds are hydrolyzed to weaker hydrogen bond hydroxyl groups linking the silicon atoms. The increase of hydroxyl ion concentration can accelerate the cracking speed of microcracks under stress. [64], [65].

$H-O-H+[\equiv S i-O-S i \equiv] \leftrightarrow[\equiv S i-O H \cdot H O-S i \equiv] \leftrightarrow 2[\equiv S i-O H]$

Afterward the samples absorb water, the hydrolysis of quartz causes stress corrosion and an area with concentration of microcracks is created in the crack tip zone. The growth of subcritical crack is associated to the moisture and the diffusion rate of water molecules [64]. During the loading process, water decreases the stress threshold of microcrack growth. Therefore, the cracks of the sample progress at smaller stress level [66]. Furthermore, the growth rate of subcritical crack in a humid environment is quicker than in dry conditions [65], [67]. Another interesting finding is that, in general terms, $\sigma_{\text {peak }}$ reduction diminishes as confining pressure increases, which suggests that at higher depths the waterweakening effect of these porous materials is less marked than at lower depths. One possible explanation for the observed behaviour may be that higher confining pressures induce micropores closure and decrease crack wall spacing and, therefore, retard stress corrosion cracking by impeding the admission of reactive elements to crack tip sites of stress corrosion [62], [66].

Additionally, water saturation could also cause the weakening of rock materials due to the development of physicochemical changes in their fabric and microstructure [68]. In this sense, the dissolution of carbonate and the debilitation of the cement present in these calcarenites could be also responsible for the observed $\sigma_{\text {peak }}$ decreases. Furthermore, the physicochemical reactions between the phyllosilicates present in these stones and water might cause their swelling, promoting the growth of initial microcracks and the formation of new cracks, which reduce the values of $\sigma_{\text {peak }}$ of the saturated specimens. Particularly, although no significant macroscopic changes in geometry of the specimens were found during saturation, 
This article can be cited as: Rabat, Á., Tomás, R., Cano, M., Miranda, T., 2020. Impact of Water on Peak and Residual Shear Strength Parameters and Triaxial Deformability of High-Porosity Building Calcarenite Stones: Interconnection with their Physical and Petrological Characteristics. Constr. Build. Mater. 262, 120789. https://doi.org/10.1016/j.conbuildmat.2020.120789.

illite can increase its volume by 50 or $60 \%$ when encounters water, causing microcracks [64]. These effects could have happened with greater intensity in R-3, which is the stone with higher clay minerals (chlorite and illite) contents. In this connection, Lin et al. [69] found that a number of wetting cycles dissolved calcite and chlorite in the rock matrix of tertiary sandstones, which in turn increased the porosity, and hence reduced the strength [69], [70].

On the other hand, concerning mechanical effects, it is well-known that, according to Terzaghi's law of effective stress [71], changes in pore pressure affect the local effective stress and therefore the bulk strength of a rock specimen for materials exhibiting a pressure sensitivity of strength [8]. Because our tests were performed under undrained conditions, the bulk compaction due to a reduction in pore volume probably caused an increase in the local pore pressure and, consequently, a reduction in effective stress, which could induce the development of local microcracks. Consequently, this phenomenon may cause one portion of the observed decrease of $\sigma_{\text {peak }}$ [72]. Nevertheless, according to previous studies performed in sandstones under undrained conditions [9], these phenomena have only a limited impact due to the increase of deviatoric stress and the additional pore spaces created by micro-cracking. In detail, when the rates of these two opposite phenomena (pore-water pressure increment due to pore closure and, new pore space creation by micro-cracking) reach an equilibrium state, pore-water pressure has achieved his peak value. Then, pore volume increment by micro-cracking becomes dominant and pore-water pressure reduces constantly [8], [9].

The effect of water on $\sigma_{\text {res }}$ for the tested materials can be seen in Fig. 10.b. Moderate decreases of $\sigma_{\text {res }}$ were obtained in the tested stones. Particularly, the reductions varied from 14.8 to $30.1 \%$ in R-1, from 9.9 to $22.1 \%$ in $\mathrm{R}-2$ and from 4.7 to $22.7 \%$ in $\mathrm{R}-3$, depending on confining pressure.

These findings indicate that $\sigma_{\text {peak }}$ is more significantly affected by water than $\sigma_{\text {res, }}$ which can be explained by the fact that an important decrease of the cohesive strength of the constituent grains of these stones happens when these specimens come into contact with water. This is probably caused by chemical processes such as the weakening of cementation between grains by dispersion or dissolution of minerals present in the building material matrix (e.g. calcite, chlorite) or the softening of the intergranular bonds [12], [15], [66] . These phenomena can also lead to an increase of porosity and, therefore, a reduction of $\sigma_{\text {peak. }}$ Furthermore, the swelling of clay minerals present in these stones when they come into contact with water can cause microcracks, leading to the deterioration of the microstructure of building materials [70], [73], [74]. In this connection, the smaller reduction of $\sigma_{\text {res }}$ in comparison with $\sigma_{\text {peak }}$ could be also attributed to the fracture plane defining $\sigma_{\text {res }}$ that is a fresh surface which was less affected by the water saturation process than the pores and pre-existing microcracks controlling the failure kinetics.

The variations of the Relative Residual Strength (RRS) (defined as: RRS $=\sigma_{\text {res }} / \sigma_{\text {peak }}$ ) caused by water for the different confining pressures are shown in Fig. 10.d. As can be seen, for all confining pressures and the three calcarenite varieties, the RRS values in saturated state are greater than the RRS values in dry state. It can be explained by the fact that $\sigma_{\text {peak }}$ was significantly more sensitive to water than $\sigma_{\text {res }}$ and that saturated specimens showed a transitional behaviour (from brittle to ductile) when confining pressure increased. Furthermore, in all materials and in both moisture conditions, RRS values increased with the confining pressure because of the limited strength drop after reaching the $\sigma_{\text {peak }}$ under higher confining pressures. This finding is in accordance with the results obtained by Wasantha and Ranjith [9].

The effect of water on $E_{\mathrm{t}}$ for the tested building stones is reflected in Fig. 10.c. The decreases of $E_{\mathrm{t}}$ due to their water saturation ranged from 5.1 to $34.7 \%$ in R-1, from 14.4 to $28.4 \%$ in R-2 and from 16.8 to $21.7 \%$ depending of confining pressure. In this line, in the same way to $\sigma_{\text {peak, }}$ generally, $E_{\mathrm{t}}$ reduction diminishes 
This article can be cited as: Rabat, Á., Tomás, R., Cano, M., Miranda, T., 2020. Impact of Water on Peak and Residual Shear Strength Parameters and Triaxial Deformability of High-Porosity Building Calcarenite Stones: Interconnection with their Physical and Petrological Characteristics. Constr. Build. Mater. 262, 120789. https://doi.org/10.1016/j.conbuildmat.2020.120789.

slightly as confining pressure increases in the tested materials and it can be explained by the abovementioned same reasons.
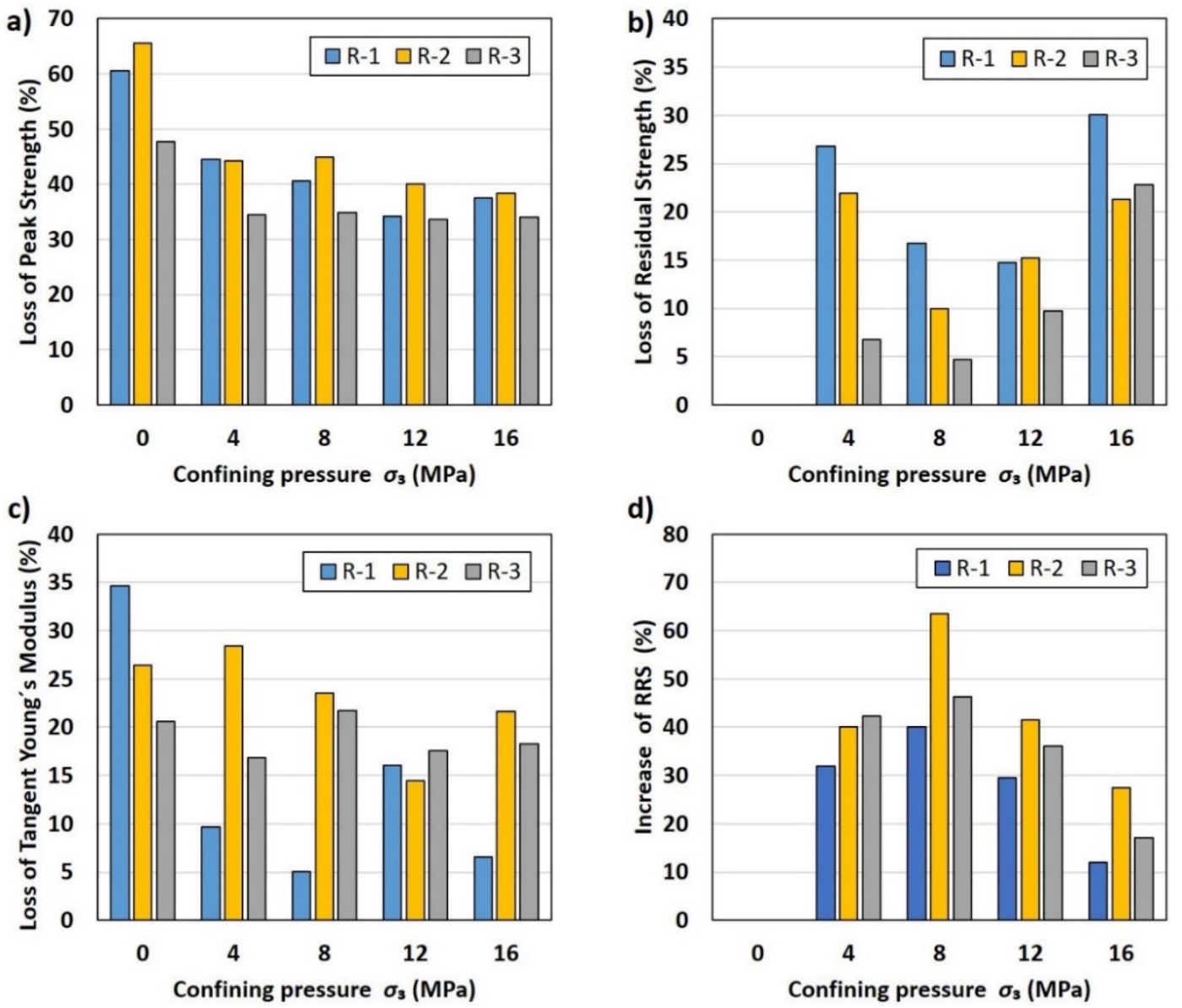

Fig. 10. Losses (\%) of peak compressive strength (a), residual compressive strength (b) and tangent Young's modulus (c) as well as increases of the relative residual strength (d) due to water for the different confining pressures in tested calcarenites.

\subsection{Impact of water on Mohr-Coulomb and Hoek-Brown shear strength parameters}

The impact of water on the Mohr-Coulomb shear strength parameters is displayed in Fig. 11. The obtained data show that $c_{\text {peak }}$ decreased significantly when samples were saturated. In particular, the percentages of reduction of $c_{\text {peak }}$ were $53.2 \%$ in R-1, 53.1\% in R-2 and 35.3\% in R-3. However, $\phi_{\text {peak }}$ diminished less intensively than $c_{\text {peak. }}$. Specifically, the obtained percentages of reduction of $\phi_{\text {peak }}$ were $4.5 \%$ in R-1, $16.2 \%$ in $\mathrm{R}-2$ and $21.7 \%$ in $\mathrm{R}-3$.

The fact that in R-1 and R-2 the percentages of reduction of $c_{\text {peak }}$ were found to be much greater than the percentages of reduction of $\phi_{\text {peak }}$ suggests that the reduction of cohesion could be considered the controlling factor for the observed peak strength decreases in these stone types. This result would be in line with the theoretical analysis performed by Vásárhelyi and Davarpanah [75] who suggested that friction angle is an intrinsic parameter of the rock which is not influenced by the moisture content. The $c_{\text {peak }}$ losses found in the three calcarenites could be attributed to physicochemical processes such as the 
This article can be cited as: Rabat, Á., Tomás, R., Cano, M., Miranda, T., 2020. Impact of Water on Peak and Residual Shear Strength Parameters and Triaxial Deformability of High-Porosity Building Calcarenite Stones: Interconnection with their Physical and Petrological Characteristics. Constr. Build. Mater. 262, 120789. https://doi.org/10.1016/j.conbuildmat.2020.120789.

weakening of cementation between the grains by dispersion or the dissolution of minerals present in the building material matrix (e.g. calcite and chlorite) [68] and the hydrolysis of quartz in crack tip regions which arouses subcritical cracks growth (stress corrosion).

The observed reduction of $\phi_{\text {peak }}$ due to water could have also been caused by the abovementioned physicochemical effects. In addition, the mechanical effects of pore pressure could also have contributed a bit to the apparent decreases of $\phi_{\text {peak. }}$ In this sense, our undrained tests do not allow to determine the exact value of the effective stress by applying the law of effective stress proposed by Terzaghi [71] because of this would require the control of the fluid pressure. However, the pore pressure clearly does not exceed the confining pressure (the sealing system would have failed during the tests). Furthermore, the pore fluid pressure probably diminishes during the undrained tests because of the volume of intergranular space rises due to the growth of microcracks before reaching the peak strength (failure) [8], [76]. Notwithstanding the foregoing, the combination of dilatancy and compression can also produce the closing of cavities contiguous to expanded pores, causing local pressures higher than the applied confining pressure in the saturated samples [76].

The smaller reduction of $c_{\text {peak }}$ found in R-3 in comparison with the other varieties could be attributed to its lower quartz and silicate content (mineral affected by stress corrosion) while its larger reduction of $\phi_{\text {peak }}$ could be explained by the greater presence of phyllosilicates in this calcarenite type. In this line, Morrow et al. [77] reported that the coefficients of friction dropped $20-60 \%$ with the addition of water for clay minerals which can take large amounts of interlayer water. Furthermore, these results are in agreement with the experimental data obtained by Li et al. [78], who reported that both $c_{\text {peak }}$ and $\phi_{\text {peak }}$ values of saturated sandstones are lower than those of dry sandstones. Additionally, in other stone types, such as granites or meta-sedimentary rock materials, important decreases of $\phi_{\text {peak }}$ due to water saturation have also been found [29], [76].

Concerning the variation of residual parameters in the three stones, an increase of $c_{\text {res }}$ and a reduction of $\phi_{\text {res }}$ were observed. Specifically, the percentages of increase of $c_{\text {res }}$ were $15.7 \%$ in R-1, 67.9\% in R-2 and $122.1 \%$ in R-3, while the percentage of reduction of $\phi_{\text {res }}$ were $15.4 \%$ in R-1, $13.3 \%$ in R-2 and $14.4 \%$ in R3. These findings are in accordance with the data obtained by Li et al. [29] in meta-siltstones, who reported that $c_{\text {res }}$ increased by $58.5 \%$ and $\phi_{\text {res }}$ decreased by $22.1 \%$. 
This article can be cited as: Rabat, Á., Tomás, R., Cano, M., Miranda, T., 2020. Impact of Water on Peak and Residual Shear Strength Parameters and Triaxial Deformability of High-Porosity Building Calcarenite Stones: Interconnection with their Physical and Petrological Characteristics. Constr. Build. Mater. 262, 120789. https://doi.org/10.1016/j.conbuildmat.2020.120789.
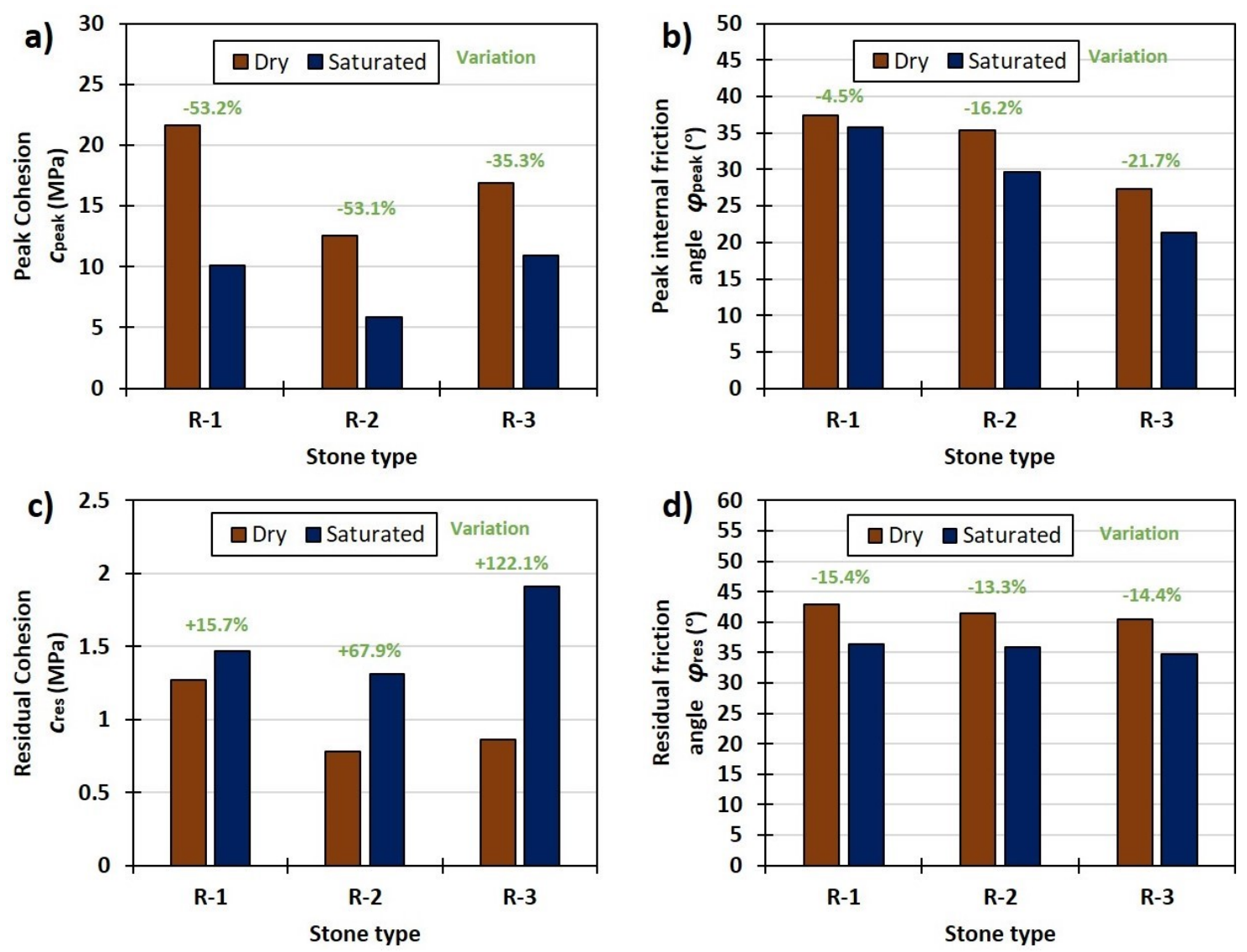

Fig. 11. Impact of water on the Mohr-Coulomb shear strength parameters obtained in the three tested building stones. Peak (a) and residual (c) cohesion, as well as, peak (b) and residual (d) friction angle.

The impact of water on the Hoek-Brown shear strength parameters is depicted in Fig. 12. On the one hand, data showed that $\sigma_{\text {cipeak }}$ diminished substantially in the three tested building materials. In particular, the percentages of reduction of $\sigma_{\text {cipeak }}$ were $59.8 \%$ in R-1, $67.3 \%$ in R-2 and $46.2 \%$ in R-3. On the other hand, data indicated that $m_{\text {ipeak }}$ changed more slightly than $\sigma_{\text {cipeak. }}$ Particularly, R-1 and R-2 exhibited increases of $m_{\text {ipeak }}$ ( $31.8 \%$ and $16.4 \%$, respectively) while a reduction was obtained in $\mathrm{R}-3$ (14.5\%). The lower presence of quartz and silicates (minerals subjected to stress corrosion) in R-3 could justify its smaller decrease of $\sigma_{\text {cipeak }}$ in comparison with the other varieties whereas the reduction of $m_{\text {ipeak }}$ in this variety could be attributed to its higher clay mineral content (phyllosilicates). Additionally, the deterioration of cement quality due to the dissolution of calcite and chlorite could explain the decrease of $\sigma_{\text {cipeak }}$ found in the three calcarenites [69], [79], [80]. In this case, only the result found in R-3 are in line with those obtained in meta-siltstones by Li et al. [29], who obtained that $\sigma_{\text {cipeak }}$ decreased by $17.6 \%$ and $m_{\text {ipeak }}$ reduced by $45.6 \%$.

Notwithstanding the above, Hoek and Brown [42] indicated that in order to be consistent with their works and to obtain reliable values of the $\mathrm{m}_{\mathrm{i}}$, it is necessary to use a range of $\sigma_{3}$ between 0.0 and $0.5 \sigma_{\mathrm{ci}}$. This condition is satisfied in all tested dry building materials but not in saturated samples of R-2 and R-3. In this connection, the values of $m_{\text {ipeak }}$ found in dry and saturated samples of R-1 (7.9 and 10.4) and R-2 (8.4 and 9.8) are similar to those reported by Hoek and Brown [42] in micritic limestones $\left(m_{i}=9\right)$ and siltstones $\left(m_{\mathrm{i}}=8\right)$ whereas the $m_{\text {ipeak }}$ values obtained in R-3 (3.5 and 4.1) are significantly smaller and closer to other lithologies such as claystone $\left(m_{\mathrm{i}}=4\right)$. 
This article can be cited as: Rabat, Á., Tomás, R., Cano, M., Miranda, T., 2020. Impact of Water on Peak and Residual Shear Strength Parameters and Triaxial Deformability of High-Porosity Building Calcarenite Stones: Interconnection with their Physical and Petrological Characteristics. Constr. Build. Mater. 262, 120789. https://doi.org/10.1016/j.conbuildmat.2020.120789.

With regard to the variation of residual strength parameters due to water, an important reduction of $\sigma_{\text {cires }}$ and a very small increase of $m_{\text {ires }}$ were found in the three studied building stones. Specifically, the percentages of reduction of $\sigma_{\text {cires }}$ were $49.1 \%$ in R-1, $46.4 \%$ in R-2 and $46.2 \%$ in R-3, while the percentages of increase of $m_{\text {ires }}$ were $1.6 \%$ in R-1, $1.0 \%$ in R-2 and $0.7 \%$ in R-3.

Concerning the comparison between peak and residual shear strength parameters obtained through Hoek-Brown criterion, it can be concluded that the failure of the building stone is linked with a reduction of the $\sigma_{\text {ci }}$ and an important increase of $m_{\mathrm{i}}$ in both dry and saturated conditions. This phenomenon can be seen in Fig. 6., where $\sigma_{\mathrm{ci}}$ is the $\mathrm{y}$-intercepts of Hoek-Brown envelopes and $\mathrm{m}_{\mathrm{i}}$ is the ratio between $\sigma_{\mathrm{ci}}$ and tensile strength ( $x$-intercepts). Similar results were obtained by Faiella et al. [81] in carbonate rock materials.

Residual failure envelopes using the Cohesion-Loss model proposed by Peng and Cai indicate that $\lambda$ parameters of the three tested calcarenites increase when they become saturated with water. Specifically, the percentage of increase were $29.5,87.2$ and $25.7 \%$ for R-1, R-2 and R-3 respectively (Fig. 12). The larger increment of $\lambda$ exhibited by $R-2$ in comparison with the other calcarenites can be attributed to the more ductile behaviour of the saturated samples of this variety. This model fits well to all residual strength datasets and has the advantages that it has only one parameter which controls the nonlinearity of the residual envelope and that can be easily programmed [41]. 
This article can be cited as: Rabat, Á., Tomás, R., Cano, M., Miranda, T., 2020. Impact of Water on Peak and Residual Shear Strength Parameters and Triaxial Deformability of High-Porosity Building Calcarenite Stones: Interconnection with their Physical and Petrological Characteristics. Constr. Build. Mater. 262, 120789. https://doi.org/10.1016/j.conbuildmat.2020.120789.
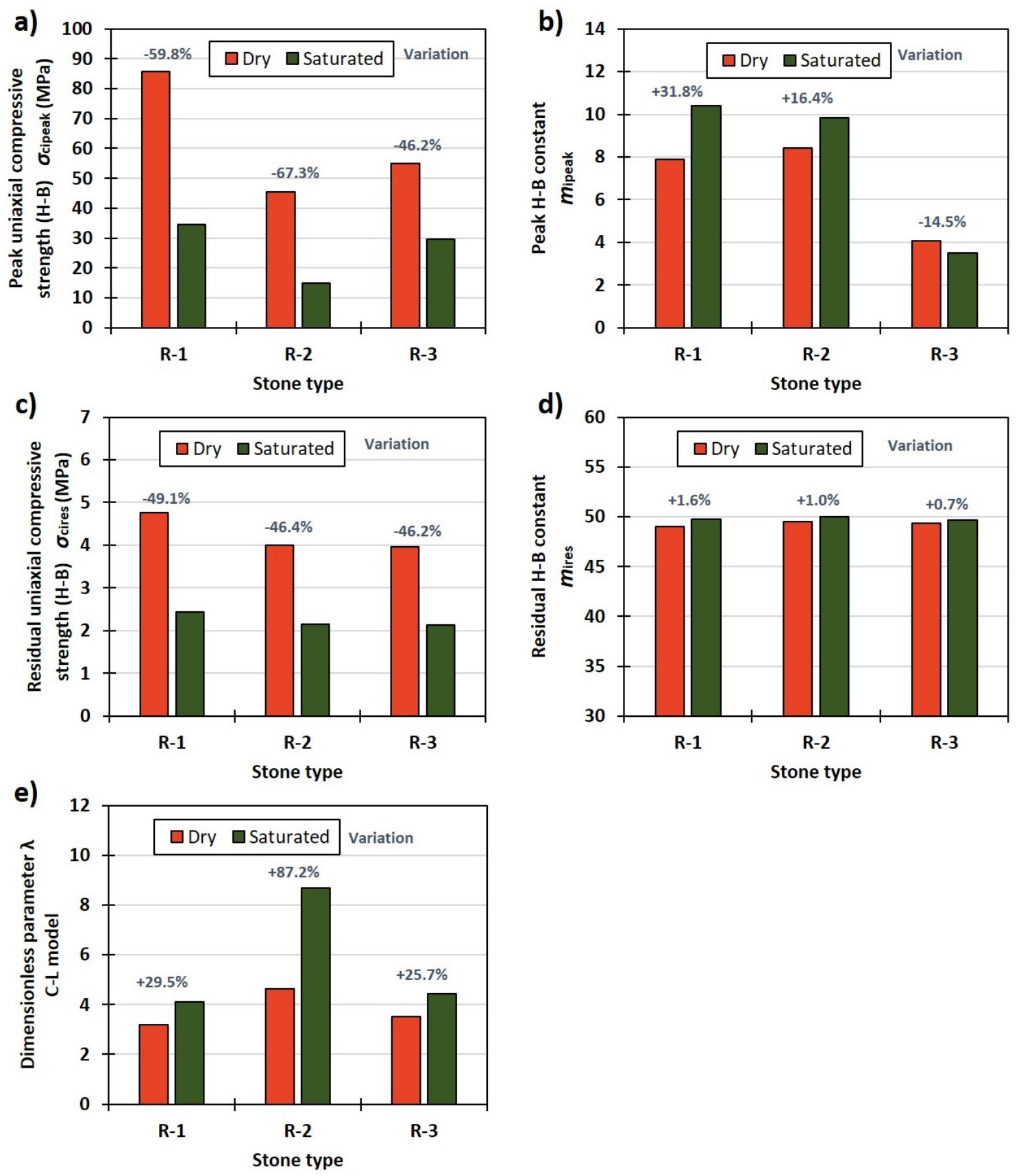

Fig. 12. Impact of water on the Hoek-Brown and Cohesion Loss shear strength parameters obtained in the three tested building stones: (a) Peak and (c) residual uniaxial compressive strengths; (b) peak and (d) residual Hoek Brown constant, and (e) $\lambda$ parameter.

In summary, the decrease of peak shear strength due to water in these building stones is found to be mainly linked with an important reduction of the cohesion and a moderate decrease of the internal friction angle in the Mohr-Coulomb failure criterion as well as with a significant loss of $\sigma_{\mathrm{ci}}$ and slighter variations on $\mathrm{m}_{\mathrm{i}}$ in the Hoek-Brown failure criterion. As for the previous properties, the main causes of this water-weakening effect might be some physicochemical processes such as the hydrolysis of quartz in crack tip regions which arouses subcritical crack growth (stress corrosion), the decrease of the 
This article can be cited as: Rabat, Á., Tomás, R., Cano, M., Miranda, T., 2020. Impact of Water on Peak and Residual Shear Strength Parameters and Triaxial Deformability of High-Porosity Building Calcarenite Stones: Interconnection with their Physical and Petrological Characteristics. Constr. Build. Mater. 262, 120789. https://doi.org/10.1016/j.conbuildmat.2020.120789.

cementation between the grains by dissolution of some minerals (calcite and chlorite) and the formations of microcracks due to the swelling of clay minerals (illite).

\section{CONCLUSIONS}

The most important results derived from this work are as follows:

(1) Triaxial compressive strength and deformability values of the tested calcarenites (R-1, R-2 and R-3) are connected with their physical characteristics. In this sense, R-1 exhibited the highest values of density, Pwave velocities and the lowest values of porosity. As a consequence, R-1 displays the greatest values of peak and residual compressive strength and Young's modulus in dry and saturated conditions and for all the different applied confining pressures. R-2 and R-3 showed smaller differences between their physical properties and, therefore, they exhibit quite similar peak and residual compressive strength values. Nevertheless, the Young's modulus values obtained in R-3 were slightly higher than those measured in R2.

(2) In dry conditions, the three tested building stones exhibited a brittle behaviour across the entire range of applied confining pressure while, in saturated conditions, the softest materials (R-2 and R-3) showed a transitional behaviour (from brittle to ductile) for the highest confining pressures values. Furthermore, it has been observed that the tangent Young's increased with confining pressure, while the angle of shear band with respect to the minor principal stress decreased with the confining pressure for the three calcarenites in both dry and saturated conditions.

(3) Significant and quite similar reductions of peak and residual compressive strength were observed in the three tested stones due to water. Furthermore, moderate and fairly similar decreases of tangent Young's modulus were also obtained for the three tested stones due to water.

(4) The water-weakening effect observed in these building stones might be explained by: a) the occurrence of several microscopic physicochemical changes such as the hydrolysis of quartz and silicates in crack tip region inducing subcritical crack growth (stress corrosion); b) the decrease of the cement quality and the deterioration of the intergranular bonds due to the dispersion or dissolution of some minerals (calcite and chlorite); and c) the formations of microcracks due to the swelling of clay minerals (illite) when they come in contact with water.

(5) Peak and residual shear strength parameters obtained through Mohr-Coulomb failure criterion varied substantially depending on the calcarenite type and were strongly influenced by water. R-1 exhibited the highest values of peak and residual values of cohesion and friction angle in dry and saturated conditions, which can be attributed to its lower porosity. Additionally, R-3 displayed a much lower peak friction angle than the other varieties in both conditions and might be explained by its higher clay mineral content and porosity. Concerning the effect of water on these parameters, peak cohesion and peak friction angle decreased in the three calcarenite varieties. It was remarkably that R-3 displayed the smallest percentage of reduction of peak cohesion due to water, which may be attributed to its lower quartz and silicate content (mineral affected by stress corrosion). Also, this calcarenite type showed the greatest percentage of reduction of the peak friction angle, which may be explained by the greater presence of phyllosilicates in its mineral composition. By contrast, residual cohesion increased significantly (although values were very small in both dry and saturated conditions) and residual friction angle reduced slightly in the three varieties due to water. 
This article can be cited as: Rabat, Á., Tomás, R., Cano, M., Miranda, T., 2020. Impact of Water on Peak and Residual Shear Strength Parameters and Triaxial Deformability of High-Porosity Building Calcarenite Stones: Interconnection with their Physical and Petrological Characteristics. Constr. Build. Mater. 262, 120789. https://doi.org/10.1016/j.conbuildmat.2020.120789.

(6) Peak and residual shear strength parameters obtained through Hoek-Brown failure criterion also fluctuated significantly depending on the calcarenite type, and were greatly modified by water. R-1 displayed the greatest value of peak unconfined compressive strength in dry and saturated conditions, which can be explained by its smaller porosity and higher density and P-wave velocity in comparison with the other varieties. Furthermore, R-3 showed a much smaller value of the peak Hoek-Brown constant $m_{\mathrm{i}}$ than the other varieties, which might be explained by its greater porosity and phyllosilicates content. Concerning the impact of water on these parameters, peak unconfined compressive strength reduced very significantly in the three building materials whereas the peak Hoek-Brown constant $m_{\mathrm{i}}$ increased in R-1 and R-2 types and decreased in R-3. Regarding the residual parameters, an important reduction of residual unconfined compressive strength and very small increases of residual Hoek-Brown constant $m_{i}$ were found in the three studied building materials due to water saturation. Furthermore, the parameter $\lambda$ of the cohesion loss model increased in the three varieties when saturated.

This study provides an in-depth insight into the changes induced by water in the peak and residual shear strength parameters of porous building stones. The obtained results will lead to accurately evaluate the safety of structural construction elements made of these materials (e.g. bridge pillars or masonry walls and dams) when are exposed to saturated environments during its lifetime (at both design and service stages). Additionally, the knowledge of the variations of compression strength and deformability with the confinement pressure give a deeper understanding of the mechanical behaviours of these materials which can be very useful in a wide range of civil engineering and architecture applications such as the assessment of the effect of retrofitting or reinforced solutions (steel elements or composite materials) on heritage stone columns which usually presents degradation caused by humidity issues related to groundwater penetration.

\section{Acknowledgements}

This research was supported by the Vice-rector of Research and Knowledge Transfer of the University of Alicante through predoctoral grant FPUUA53-2018 and projects UAUSTI18-21, UAUSTI19-25, UAEEBB2018-09 and GRE18-15 and by the Spanish Ministry of Economy and Competitiveness (MINECO) through the project TEC2017- 85244-C2-1-P. The authors thank to professor J.C. Cañaveras (University of Alicante) for allowing them to perform the thin-section analyses in his laboratory and to professor D. Benavente (University of Alicante) for his help with interpretation of XRD results. They also thank the company "Bateig Piedra Natural S.A" for providing rock material used in this work. Finally, we thank the two anonymous reviewers whose comments and suggestions helped improve and clarify this manuscript.

\section{References}

[1] T. Wong, C. David, and W. Zhu, "The transition from brittle faulting to cataclastic flow in porous sandstones: Mechanical deformation," J. Geophys. Res. Solid Earth, vol. 102, no. B2, pp. 3009-3025, 1997.

[2] T. E. Scott and K. . Nielsen, "The effect of porosity on the brittle ductile transition in sandstones," J. Geophys. Res., vol. 96, pp. 405-414, 1991.

[3] P. Baud, W. Zhu, and T. Wong, "Failure mode and weakening effect of water on sandstone," J. Geophys. Res. Res., vol. 105, pp. 16371-16389, 2000.

[4] J. L. Lerma, M. Cabrelles, and C. Portalés, "Multitemporal thermal analysis to detect moisture on a building facade," Constr. Build. Mater., vol. 25, no. 5, pp. 2190-2197, 2011.

[5] A. Moropoulou, K. C. Labropoulos, E. T. Delegou, M. Karoglou, and A. Bakolas, "Non-destructive techniques as a tool for the protection of built cultural heritage," Constr. Build. Mater., vol. 48, pp. 1222-1239, 2013. 
This article can be cited as: Rabat, Á., Tomás, R., Cano, M., Miranda, T., 2020. Impact of Water on Peak and Residual Shear Strength Parameters and Triaxial Deformability of High-Porosity Building Calcarenite Stones: Interconnection with their Physical and Petrological Characteristics. Constr. Build. Mater. 262, 120789. https://doi.org/10.1016/j.conbuildmat.2020.120789.

[6] M. Korkanç, "Deterioration of different stones used in historical buildings within Nigde province, Cappadocia," Constr. Build. Mater., vol. 48, pp. 789-803, 2013.

[7] P. Vázquez et al., "Evaluation of the petrophysical properties of sedimentary building stones in order to establish quality criteria," Constr. Build. Mater., vol. 41, pp. 868-878, 2013.

[8] M. Duda and J. Renner, "The weakening effect of water on the brittle failure strength of sandstone," Geophys. J. Int., vol. 192, no. 3, pp. 1091-1108, 2013.

[9] P. L. P. Wasantha and P. G. Ranjith, "Water-weakening behavior of Hawkesbury sandstone in brittle regime," Eng. Geol., vol. 178, pp. 91-101, 2014.

[10] N. J. Price, "The compressive strength of coal measure rocks," Colliery Eng., vol. 37, no. 437, pp. 283-292, 1960.

[11] R. L. Mann and I. Fatt, "Effect of pore fluids on the elastic properties of sandstone," Geophysics, vol. 25, no. 2, pp. 433-444, Apr. 1960.

[12] C. G. Dyke and L. Dobereiner, "Evaluating the strength and deformability of sandstones," Q. J. Eng. Geol. Hydrogeol., vol. 24, no. 1, pp. 123-134, 1991.

[13] A. B. Hawkins and B. J. McConnell, "Sensitivity of sandstone strength and deformability to changes in moisture content," Q. J. Eng. Geol. Hydrogeol., vol. 25, no. 2, pp. 115-130, 1992.

[14] A. Shakoor and E. H. Barefield, "Relationship between unconfined compressive strength and degree of saturation for selected sandstones," Environ. Eng. Geosci., vol. 15, no. 1, pp. 29-40, 2009.

[15] E. Verstrynge, R. Adriaens, J. Elsen, and K. Van Balen, "Multi-scale analysis on the influence of moisture on the mechanical behavior of ferruginous sandstone," Constr. Build. Mater., vol. 54, pp. 78-90, 2014.

[16] G. R. Lashkaripour and R. Ajalloeian, "The Effect Of Water Content On The Mechanical Behaviour Of FineGrained Sedimentary Rocks," ISRM International Symposium. International Society for Rock Mechanics and Rock Engineering, Melbourne, Australia, 2000.

[17] Q. Jiang, J. Cui, X. Feng, and Y. Jiang, "Application of computerized tomographic scanning to the study of water-induced weakening of mudstone," Bull. Eng. Geol. Environ., vol. 73, no. 4, pp. 1293-1301, 2014.

[18] B. Vásárhelyi, "Statistical analysis of the influence of water content on the strength of the miocene limestone," Rock Mech. Rock Eng., vol. 38, no. 1, pp. 69-76, 2005.

[19] F. Cherblanc, J. Berthonneau, P. Bromblet, and V. Huon, "Influence of Water Content on the Mechanical Behaviour of Limestone: Role of the Clay Minerals Content," Rock Mech. Rock ..., vol. 49, no. 6, p. 2033.2042, 2016.

[20] Á. Török and B. Vásárhelyi, "The influence of fabric and water content on selected rock mechanical parameters of travertine, examples from Hungary," Eng. Geol., vol. 115, no. 3-4, pp. 237-245, 2010.

[21] Z. A. Erguler and R. Ulusay, "Water-induced variations in mechanical properties of clay-bearing rocks," Int. J. Rock Mech. Min. Sci., vol. 46, no. 2, pp. 355-370, 2009.

[22] I. Yilmaz, "Influence of water content on the strength and deformability of gypsum," Int. J. Rock Mech. Min. Sci., vol. 47, no. 2, pp. 342-347, 2010.

[23] Á. Rabat, M. Cano, R. Tomás, E. Tamayo, and L. R. Alejano, "Evaluation of Strength and Deformability of Soft Sedimentary Rocks in Dry and Saturated Conditions Through Needle Penetration and Point Load Tests: A Comparative Study," Rock Mech. Rock Eng., vol. 53, no. 6, pp. 2707-2726, 2020.

[24] C. David, B. Menendez, W. Zhu, and T. F. Wong, "Mechanical compaction, microstructures and permeability evolution in sandstones," Phys. Chem. Earth, Part A Solid Earth Geod., vol. 26, no. 1-2, pp. 45-51, 2001.

[25] K. Mair, S. Elphick, and I. Main, "Influence of confining pressure on the mechanical and structural evolution of laboratory deformation bands," Geophys. Res. Lett., vol. 29, no. 10, pp. 49-1-49-4, 2002.

[26] Z. Li, Y. Sheng, and D. J. Reddish, "Rock strength reduction and its potential environmental consequences as a result of groundwater rebound," in 9th InternationalMine Water Congress, 2005, pp. 513-519. 
This article can be cited as: Rabat, Á., Tomás, R., Cano, M., Miranda, T., 2020. Impact of Water on Peak and Residual Shear Strength Parameters and Triaxial Deformability of High-Porosity Building Calcarenite Stones: Interconnection with their Physical and Petrological Characteristics. Constr. Build. Mater. 262, 120789. https://doi.org/10.1016/j.conbuildmat.2020.120789.

[27] C. Chang and B. Haimson, "Effect of fluid pressure on rock compressive failure in a nearly impermeable crystalline rock: Implication on mechanism of borehole breakouts," Eng. Geol., vol. 89, no. 3-4, pp. 230242, 2007.

[28] N. Reviron, T. Reuschlé, and J. D. Bernard, "The brittle deformation regime of water-saturated siliceous sandstones," Geophys. J. Int., vol. 178, no. 3, pp. 1766-1778, 2009.

[29] D. Li, L. N. Y. Wong, G. Liu, and X. Zhang, "Influence of water content and anisotropy on the strength and deformability of low porosity meta-sedimentary rocks under triaxial compression," Eng. Geol., vol. 126, pp. 46-66, 2012.

[30] P. Bésuelle, J. Desrues, and S. Raynaud, "Experimental characterisation of the localisation phenomenon inside a Vosges sandstone in a triaxial cell," Int. J. Rock Mech. Min. Sci., vol. 37, no. 8, pp. 1223-1237, 2000.

[31] J. Sulem and H. Ouffroukh, "Shear-banding in drained and undrained triaxial tests on a saturated sandstone ; porosity and permeability evolution," Int. J. Rock Mech. Min. Sci., vol. 43, no. 2, pp. 292-310, 2007.

[32] Á. Rabat, M. Cano, and R. Tomás, "Effect of water saturation on strength and deformability of building calcarenite stones: Correlations with their physical properties," Constr. Build. Mater., vol. 232, pp. 1-15, 2020.

[33] L. Estevan, F. J. Baeza, A. Maciá, and S. Ivorra, "FRP Confinement of Stone Specimens Subjected to Moisture and Preload," Int. J. Archit. Herit., pp. 1-14, 2020.

[34] F. J. Baeza, S. Ivorra, D. Bru, and F. B. Varona, "Dynamic evaluation of a historic fountain under blast loading," Procedia Eng., vol. 199, pp. 3308-3313, 2017.

[35] ISRM, "Suggested methods for determining the strength of rock materials in triaxial compression: Revised version," Int. J. Rock Mech. Min. Sci. Geomech., vol. 20, no. 6, pp. 285-290, 1983.

[36] J. Arzúa, J. González, I. Erazo, M. Canovás, and L. R. Alejano, "Grinding or not grinding , that is the question," in 14th International Congress on Rock Mechanics and Rock Engineering (ISRM 2019) - Rock Mechanics for Natural Resources and Infrastructure Development, 2019, pp. 2195-2202.

[37] AENOR, "UNE-EN 1936. Métodos de ensayo para piedra natural. Determinación de la densidad real y aparente y de la porosidad abierta y total.," Asoc. Española Norm. y Certificación, Madrid., 2007.

[38] AENOR, “UNE 103-302-94. Determinación de la densidad relativa de las partículas de un suelo.," Asoc. Española Norm. y Certificación, Madrid., p. 4, 1994.

[39] AENOR, "UNE-EN 14579. Método de ensayo para piedra natural. Determinación de la velocidad de propagación del sonido.," Asoc. Española Norm. y Certificación, Madrid., 2005.

[40] ISRM, "The Complete ISRM Suggested Methods for Rock Characterization, Testing and Monitoring: 19742006," Commission on Testing Methods, International Society for Rock Mechanics. ISRM Turkish National Group, Ankara. 3. 2007.

[41] J. Peng and M. Cai, "A cohesion loss model for determining residual strength of intact rocks," Int. J. Rock Mech. Min. Sci., vol. 119, no. May, pp. 131-139, 2019.

[42] E. Hoek and E. T. Brown, "Practical estimates of rock mass strength," Int. J. Rock Mech. Min. Sci., vol. 34, no. 8, pp. 1165-1186, 1997.

[43] E. Hoek, "Strength of jointed rock masses," Geotechnique, vol. 33, no. 3, pp. 187-223, 1983.

[44] F. Gao and H. Kang, "Experimental Study on the Residual Strength of Coal Under Low Confinement," Rock Mech. Rock Eng., vol. 50, no. 2, pp. 285-296, 2017.

[45] Rocscience Inc, “RocData v.5.0." Toronto, Ontario, Canada, 2017.

[46] R. Folk, "Spectral subdivision of limestone types," in Classification of Carbonate Rocks. Memoir-American Association of Petroleum Geologists, W. E. Ham, Ed. 1962, pp. 62-84.

[47] S. Ordoñez, M. Louis, M. A. García del Cura, R. Fort, M. C. López de Azcona, and F. Mingarro, “Physical 
This article can be cited as: Rabat, Á., Tomás, R., Cano, M., Miranda, T., 2020. Impact of Water on Peak and Residual Shear Strength Parameters and Triaxial Deformability of High-Porosity Building Calcarenite Stones: Interconnection with their Physical and Petrological Characteristics. Constr. Build. Mater. 262, 120789. https://doi.org/10.1016/j.conbuildmat.2020.120789.

properties and petrographic characteristics of some Bateig stone varieties," in 7th International IAEG Congress, 1994, pp. 3595-3603.

[48] A. La Iglesia, M. A. García del Cura, S. Ordoñez, and A. Bernabéu, "Estudio de los filosilicatos de la 'Piedra Bateig' (Neógeno de la provincia de Alicante)," Geogaceta, vol. 23, pp. 79-82, 1998.

[49] V. Brotons et al., "Improved correlation between the static and dynamic elastic modulus of different types of rocks," Mater. Struct. Constr., vol. 49, no. 8, pp. 3021-3037, 2016.

[50] S. Assefa, C. McCann, and J. Sothcott, "Velocities of compressional and shear waves in limestones," Geophys. Prospect., vol. 51, no. 1, pp. 1-13, 2003.

[51] G. Walton, D. Labrie, and L. R. Alejano, "On the Residual Strength of Rocks and Rockmasses," Rock Mech. Rock Eng., vol. 52, no. 11, pp. 4821-4833, 2019.

[52] J. Arzúa and L. R. Alejano, "Dilation in granite during servo-controlled triaxial strength tests," Int. J. Rock Mech. Min. Sci., vol. 61, pp. 43-56, 2013.

[53] T. N. Gowd and F. Rummel, "Effect of Confining Pressure on the Fracture Behaviour of a Porous Rock," Int. J. Rock Mech. Min. Sci. Geomech. Abstr., vol. 17, pp. 225-229, 1980.

[54] E. Kim, M. A. Stine, D. B. M. de Oliveira, and H. Changani, "Correlations between the physical and mechanical properties of sandstones with changes of water content and loading rates," Int. J. Rock Mech. Min. Sci., vol. 100, no. August 2016, pp. 255-262, 2017.

[55] M. A. Rajabzadeh, Z. Moosavinasab, and G. Rakhshandehroo, "Effects of rock classes and porosity on the relation between uniaxial compressive strength and some rock properties for carbonate rocks," Rock Mech. Rock Eng., vol. 45, no. 1, pp. 113-122, 2012.

[56] R. A. Plumb, "Influence of composition and texture on the failure properties of clastic rocks," in Eurock 1994 Rock Mechanics in Petroleum Engineering, 1994, pp. 13-20.

[57] V. Hajiabdolmajid, P. K. Kaiser, and C. D. Martin, "Modelling brittle failure of rock," Int. J. Rock Mech. Min. Sci., vol. 39, pp. 731-741, 2002.

[58] S. Q. Yang, H. W. Jing, and S. Y. Wang, "Experimental investigation on the strength, deformability, failure behavior and acoustic emission locations of red sandstone under triaxial compression," Rock Mech. Rock Eng., vol. 45, no. 4, pp. 583-606, 2012.

[59] M. J. Heap, P. Baud, P. G. Meredith, A. F. Bell, and I. G. Main, "Time-dependent brittle creep in darley dale sandstone," J. Geophys. Res. Solid Earth, vol. 114, no. 7, pp. 1-22, 2009.

[60] Z. Li, L. Wang, Y. Lu, W. Li, and K. Wang, "Experimental Investigation on the Deformation, Strength, and Acoustic Emission Characteristics of Sandstone under True Triaxial Compression," Adv. Mater. Sci. Eng., pp. $1-16,2018$.

[61] T. A. Michalske and S. W. Freiman, "A molecular interpretation of stress corrosion in silica," Nature, vol. 295, no. 5849. pp. 511-512, 1982.

[62] B. K. Atkinson and P. G. Meredith, "The theory of subcritical crack growth with applications to minerals and rocks," in Fracture Mechanics of Rocks, B. K. Atkinson, Ed. London: Academic Press, 1987, pp. 111-166.

[63] B. K. Atkinson and P. G. Meredith, "Stress corrosion cracking of quartz: A note on the influence of chemical environment," Tectonophysics, vol. 77, no. 1-2, pp. 1-11, 1981.

[64] B. Li et al., "Experimental study on the mechanical properties weakening mechanism of siltstone with different water content," Arab. J. Geosci., vol. 12, no. 21, 2019.

[65] Y. Nara, K. Morimoto, T. Yoneda, N. Hiroyoshi, and K. Kaneko, "Effects of humidity and temperature on subcritical crack growth in sandstone," Int. J. Solids Struct., vol. 48, no. 7-8, pp. 1130-1140, 2011.

[66] J. Hadizadeh and R. D. Law, "Water-weakening of sandstone and quartzite deformed at various stress and strain rates," Int. J. Rock Mech. Min. Sci. Geomech. Abstr., vol. 28, no. 5, pp. 431-439, 1991.

[67] B. K. Atkinson, "A fracture mechanics study of subcritical tensile cracking of quartz in wet environments," 
This article can be cited as: Rabat, Á., Tomás, R., Cano, M., Miranda, T., 2020. Impact of Water on Peak and Residual Shear Strength Parameters and Triaxial Deformability of High-Porosity Building Calcarenite Stones: Interconnection with their Physical and Petrological Characteristics. Constr. Build. Mater. 262, 120789. https://doi.org/10.1016/j.conbuildmat.2020.120789.

Pure Appl. Geophys., vol. 117, no. 5, pp. 1011-1024, 1979.

[68] M. Romana and B. Vásárhelyi, "A discussion on the decrease of unconfined compressive strength between saturated and dry rock samples," Proc. 11th Congr. Int. Soc. rock Mech., vol. 1, pp. 139-142, 2007.

[69] M. L. Lin, F. S. Jeng, L. S. Tsai, and T. H. Huang, "Wetting weakening of tertiary sandstones-microscopic mechanism," Environ. Geol., vol. 48, no. 2, pp. 265-275, 2005.

[70] L. N. Y. Wong, V. Maruvanchery, and G. Liu, "Water effects on rock strength and stiffness degradation," Acta Geotech., vol. 11, no. 4, pp. 713-737, 2016.

[71] K. Terzaghi, Erdbaumechanik auf bodenphysikalischer Grundlage. Deuticke, reissued Wien, 1925.

[72] Y. Bernabe and W. F. Brace, "Deformation and fracture of Berea sandstone," in The Brittle-Ductile Transition in Rocks, vol. 56, A. G. Duba, W. B. Durham, J. W. Handin, and H. F. Wang, Eds. Washington, DC.: Geophysical Monograph Series, AGU, 1990, pp. 91-101.

[73] M. Tiennot, J. D. Mertz, and A. Bourgès, "Influence of Clay Minerals Nature on the Hydromechanical and Fracture Behaviour of Stones," Rock Mech. Rock Eng., vol. 52, no. 6, pp. 1599-1611, 2019.

[74] M. M. Demarco, E. Jahns, J. Rüdrich, P. Oyhantcabal, and S. Siegesmund, "The impact of partial water saturation on rock strength: an experimental study on sandstone," Zeitschrift der Dtsch. Gesellschaft für Geowissenschaften, vol. 158, no. 4, pp. 869-882, 2007.

[75] B. Vásárhelyi and M. Davarpanah, "Influence of water content on the mechanical parameters of the intact rock and rock mass," Period. Polytech. Civ. Eng., vol. 62, no. 4, pp. 1060-1066, 2018.

[76] E. Althaus, A. Friz-Töpfer, C. Lempp, and O. Natau, "Effects of water on strength and failure mode of coarse-grained granites at $300^{\circ} \mathrm{C}$," Rock Mech. Rock Eng., vol. 27, no. 1, pp. 1-21, 1994.

[77] C. A. Morrow, D. E. Moore, and D. A. Lockner, "The effect of mineral bond strength and adsorbed water on fault gouge frictional strength," Geophys. Res. Lett., vol. 27, no. 6, pp. 815-818, 2000.

[78] D. Li, Z. Sun, Q. Zhu, and K. Peng, "Triaxial loading and unloading tests on dry and saturated sandstone specimens," Appl. Sci., vol. 9, no. 8, pp. 1-19, 2019.

[79] X. G. Zhao and M. Cai, "Influence of plastic shear strain and confinement-dependent rock dilation on rock failure and displacement near an excavation boundary," Int. J. Rock Mech. Min. Sci., vol. 47, no. 5, pp. 723$738,2010$.

[80] J. Shen and M. Karakus, "Simplified method for estimating the Hoek-Brown constant for intact rocks," J. Geotech. Geoenvironmental Eng., vol. 140, no. 6, pp. 1-8, 2014.

[81] D. Faiella, R. Ribacchi, and A. Garino, "Mechanical properties of a pervasively fractured carbonate rock mass," in ISRM Symposium: EUROCK'92, 1992. 